\title{
Clustering symptoms of non-severe malaria in semi-immune Amazonian patients
}

Antonio C Martins, Felipe M Araújo, Cássio B Braga, Maria G S Guimarães, Rudi Nogueira, Rayanne A Arruda, Lícia N Fernandes, Livia R Correa, Rosely S Malafronte, Oswaldo G Cruz, Claudia T Codeço, Mônica da Silva-Nunes

Malaria is a disease that generates a broad spectrum of clinical features. The purpose of this study was to evaluate the clinical spectrum of malaria in semi-immune populations. Patients were recruited in Mancio Lima, a city situated in the Brazilian Amazon region. The study included 171 malaria cases, which were diagnosed via the use of a thick blood smear and confirmed by molecular methods. A questionnaire addressing 19 common symptoms was administered to all patients. Multiple correspondence analysis and hierarchical cluster analysis were performed to identify clusters of symptoms, and logistic regression was used to identify factors associated with the occurrence of symptoms. The cluster analysis revealed five groups of symptoms: The first cluster, which included algicand fever-related symptoms, occurred in up to $95.3 \%$ of the cases. The second cluster, which comprised gastric symptoms (nausea, abdominal pain, inappetence, and bitter mouth), occurred in frequencies that ranged between $35.1 \%$ and $42.7 \%$, and at least one of these symptoms was observed in $71.9 \%$ of the subjects. All respiratory symptoms were clustered and occurred in $42.7 \%$ of the malaria cases, and diarrhea occurred in $9.9 \%$ of the cases. Symptoms constituting the fifth cluster were vomiting and pallor, with a $14.6 \%$ and $11.7 \%$ of prevalence, respectively. A higher parasitemia count (more than 300 parasites $/ \mathrm{mm}^{3}$ ) was associated with the presence of fever, vomiting, dizziness, and weakness $(P<0.05)$. Arthralgia and myalgia were associated with patients over the age of 14 years $(P<0.001)$. Having experienced at least eight malaria episodes prior to the study was associated with a decreased risk of chills and fever and an increased risk of sore throat $(P<0.05)$. None of the symptoms showed an association with gender or with species of Plasmodium. The clinical spectrum of malaria in semi-immune individuals can have a broad range of symptoms, the frequency and intensity of which are associated with age, past exposure to malaria, and parasitemia. Understanding the full spectrum of nonsevere malaria is important in endemic areas to guide both passive and active case detection, for the diagnosis of malaria in travelers returning to non-endemic areas, and for the development of vaccines aimed to decrease symptom severity. 
2 Antonio C Martins ${ }^{1}$, Felipe M Araújo ${ }^{1}$, Cássio B Braga ${ }^{1}$, Maria Gabriela S Guimarães ${ }^{1}$, Rudi Nogueira ${ }^{1}$, Rayanne A

3 Arruda $^{1}$, , Lícia N Fernandes², Livia R Correa², Rosely S Malafronte², Oswaldo G Cruz ${ }^{3}$, Claudia T Codeço ${ }^{3}$, Mônica da 4 Silva-Nunes ${ }^{1 *}$.

${ }^{1}$ Health Sciences Centre, Federal University of Acre, Rio Branco, Acre, Brazil

$7 \quad$ 3Scientific Computing Program, Oswaldo Cruz Foundation, Rio de Janeiro, RJ, Brazil

82 Tropical Medicine Institute, University of São Paulo, São Paulo, Brazil

$9 *$ corresponding author

Corresponding author:

Mônica da Silva-Nunes - Health Sciences Centre, Federal University of Acre, BR 364 KM 04, Rio 
Abstract

Malaria is a disease that generates a broad spectrum of clinical features. The purpose of this study was to evaluate the clinical spectrum of malaria in semi-immune populations. Patients were recruited in Mancio Lima, a city situated in the Brazilian Amazon region. The study included 171 malaria cases, which were diagnosed via the use of a thick blood smear and confirmed by molecular methods. A questionnaire addressing 19 common symptoms was administered to all patients. Multiple correspondence analysis and hierarchical cluster analysis were performed to identify clusters of symptoms, and logistic regression was used to identify factors associated with the occurrence of symptoms. The cluster analysis revealed five groups of symptoms: The first cluster, which included algic- and fever-related symptoms, occurred in up to $95.3 \%$ of the cases. The second cluster, which comprised gastric symptoms (nausea, abdominal pain, inappetence, and bitter mouth), occurred in frequencies that ranged between $35.1 \%$ and $42.7 \%$, and at least one of these symptoms was observed in $71.9 \%$ of the subjects. All respiratory symptoms were clustered and occurred in $42.7 \%$ of the malaria cases, and diarrhea occurred in $9.9 \%$ of the cases. Symptoms constituting the fifth cluster were vomiting and pallor, with a $14.6 \%$ and $11.7 \%$ of prevalence, respectively. A higher parasitemia count

41 (more than 300 parasites $/ \mathrm{mm}^{3}$ ) was associated with the presence of fever, vomiting, dizziness, and weakness $(P<0.05)$. Arthralgia and myalgia were associated with patients over the age of 14 years $(P<0.001)$. Having experienced at least eight malaria episodes prior to the study was associated with a decreased risk of chills and fever and an increased risk of sore throat $(\mathrm{P}<$ 0.05). None of the symptoms showed an association with gender or with species of Plasmodium. 
47 The clinical spectrum of malaria in semi-immune individuals can have a broad range of symptoms, the frequency and intensity of which are associated with age, past exposure to malaria, and parasitemia. Understanding the full spectrum of nonsevere malaria is important in endemic areas to guide both passive and active case detection, for the diagnosis of malaria in travelers returning to non-endemic areas, and for the development of vaccines aimed to decrease symptom severity.

Keywords: Malaria; Symptoms cluster; Amazon; Multiple correspondence analysis; Clinical features

\section{Introduction}

Malaria features a broad spectrum of clinical outcomes that vary from asymptomatic infection (da Silva-Nunes et al., 2012) to severe disease (O’Brien, Ramírez, \& Martínez, 2014), associated with profound anemia, jaundice, coma, plaquetopenia, respiratory distress, and cerebral malaria. Between asymptomatic presentation and cases that may progress to coma and death lies the clinical spectrum of nonsevere malaria, which generally occurs in semiimmune individuals.

The most easily recognizable symptoms in nonsevere malaria are chills, fever, and sweating, which are frequently observed in patients experiencing the first episode of malaria, a stage during which they have no immunity (López-Vélez et al., 1999). However, semi-immune patients may experience several other symptoms, such as headache, myalgia, arthralgia, weakness, abdominal pain and others, which can be helpful in the clinical diagnosis of nonsevere malaria (da Silva-Nunes \& Ferreira, 2007; Périssé \& Strickland, 2008). 
67 In general, diagnostic methods applied in malaria-endemic areas are heterogeneous in nature.

68

In some countries, malaria is treated after a clinical diagnosis because of limited access to laboratory tests. To this effect, sensitivity and specificity of symptoms and signals are crucial for medical care because certain symptoms can be nonspecific and may be associated with other diseases; as a result, a patient may be misdiagnosed and receive the wrong treatment, which can have detrimental effects on his or her health (Ansmana et al., 2013).

Other malaria-endemic areas use rapid tests, but such tests can yield false negative results, especially in the cases of low parasitemia counts, commonly seen in patients with asymptomatic infections (Okell et al., 2012). In most endemic settings, however, thick smears are widely used for malaria diagnosis because they are least expensive and easy to perform. However, even with well-trained human resources thick smears can yield false negative results in cases with low parasitemia.

Throughout Brazil, thick smears or rapid tests are administered at no cost to patients, and cases are detected using either passive or active methods. Passive methods are applied when a patient seeks diagnosis and treatment after experiencing a few days of sickness. Active methods are used by healthcare workers when examining potential cases among both sick and asymptomatic individuals. The Brazilian Ministry of Health (Ministério da Saúde, 2005) recommends that treatment be provided only after laboratory confirmation of malaria, either by thick smear, rapid diagnostic tests (RDTs), or, less commonly, by polymerase chain reaction (PCR).

Although the control of malaria requires the identification of a Plasmodium infection during a short prodromal asymptomatic period or during a long-lasting asymptomatic case 
89

90

91

92

(Matangila et al., 2014), testing every asymptomatic individual who lives in an endemic area and who could be in a prodromal period can be expensive; therefore, active case detection generally focuses on sick patients, especially in rural areas such as the Amazon, where one must travel a long distance to reach a patient's house. Identifying the most common malaria symptoms, as well as the less frequent ones, can thus enhance the active detection strategy in settings with few resources and in which testing everybody is not feasible.

In addition to optimizing diagnosis and malaria control, the description of clinical heterogeneity in semi-immune individuals provides more accurate endpoints for vaccine efficacy studies, which can be used when evaluating semi-immune individuals in endemic countries (Roestenberg et al., 2012). Such vaccine trials may target the reduction of symptoms as a primary or secondary endpoint. For instance, an antimalarial vaccine may not prevent malaria, but the acquired immunity may reduce peripheral parasitemia and thus result in a less pronounced clinical picture. In this case, the quantification of symptoms and their reduction may be a valuable tool in determining vaccine efficacy.

Knowledge of all possible scenarios or clinical presentations of malaria, especially in the absence of fever, is important in the diagnosis of malaria in nonimmune and semi-immune individuals who live in malaria-free areas and who are seeking treatment. A review of malaria deaths occurring in several countries between 1985 and 2013 was performed, gathering 1 study published in 1985, 16 studies published between 1990 and 1999 and 34 studies published after 2000 . This review revealed that $67.8 \%$ of the U.S. travelers who died of malaria did not receive a correct diagnosis on the same day they presented at the inpatient service, and in $17.9 \%$ of the fatal cases, diagnoses were made only during the autopsy (Lüthi \& Schlagenhauf, 
111 2015). In the UK and in Switzerland, malaria-related deaths were more frequently observed

112 within services whose medical staff members were not accustomed to seeing malaria patients

113 (Lüthi \& Schlagenhauf, 2015).

114 Materials and Methods

115 Study area and population

116 This study was conducted in Mancio Lima, Acre, in the western Brazilian Amazon region.

117 Mancio Lima is 5,453 $\mathrm{km}^{2}$ in area and has 16,795 inhabitants living in urban (57.3\%), rural or

118 riparian (37.9\%), and indigenous (4.8\%) areas (IBGE, 2010). The city, located $38 \mathrm{~km}$ from

119 Cruzeiro do Sul and $650 \mathrm{~km}$ northwest of Rio Branco, borders the municipality of Cruzeiro do

120 Sul and Rodrigues Alves to the east, Amazonas state to the north, and Peru to the west. Mancio

121 Lima is an equatorial region surrounded by palm trees and rainforests (Acre, 2010). Its

122 monsoon season occurs from November to April, with an annual rainfall of $1,600-2,750 \mathrm{~mm}$.

123 The city's annual temperature ranges between $20^{\circ} \mathrm{C}$ and $32{ }^{\circ} \mathrm{C}$, and the annual relative

124 humidity is $80-90 \%$ (Acre, 2010). In 2010, the human development index was 0.625 . The

125 economy's main sources of income are cattle-raising, fishing, and producing and selling banana

126 and cassava products.

In 2010, there were 5,729 autochthonous malaria cases within a total population of

16,795 , resulting in an incidence rate of $34.11 \%$. About $40 \%$ of those cases occurred in the urban areas of the city. In 2013, Mancio Lima registered 6,936 cases of malaria, of which $29.1 \%$

130 were falciparum malaria and $70.3 \%$ vivax malaria; only $0.6 \%$ of the cases were of mixed species

131 (Ministério da Saúde, 2015). 
132

133

134

135

136

137

138

\section{Population and sampling}

Participants were sourced from malaria cases that were diagnosed using passive case detection at health posts in Mancio Lima during the months of February, June, and November of 2012 and in May 2013. Except for June, all other months corresponded to the rainy season, when the cases are most prevalent. Patients with malaria symptoms and seeking a diagnosis were first submitted to a thick blood smear by health agents. Patients who tested positive and who were more than 5 years of age were asked to participate in the study; if they agreed to undergo an interview and blood sampling, they were included in the study. An age cutoff point

of 5 years was chosen based on previous experience with questionnaire answers and graduating symptoms (da Silva-Nunes \& Ferreira, 2007). Only children who provided reliable information were included in the study. For minors, consent by the patient and by the patient's parent or guardian was obtained. Participants were interviewed using a structured questionnaire that included demographic variables (e.g., gender and age), frequency of symptoms, and number of previous malaria episodes, among other factors. Blood samples were collected intravenously (when allowed) or by finger prick. All clinical interviews were performed by the same researcher (ACM), who had previously been trained by a malariologist (MdSN).

\section{Blood sampling and laboratory diagnosis of malaria}

$$
\text { Thick blood smears were stained with Giemsa. According to Ministry of Health }
$$
guidelines (Ministério da Saúde, 2005), at least 100 fields were examined for malaria parasites by two experienced microscopists, using $700 \times$ magnification to conduct a semi-quantitative analysis of parasitemia ( $<200$ parasites $/ \mathrm{mm}^{3}, 200-300$ parasites $/ \mathrm{mm}^{3}, 301-500$ parasites $/ \mathrm{mm}^{3}$, 
153

501-10.000 parasites $/ \mathrm{mm}^{3}$, and $>10.000$ parasites $/ \mathrm{mm}^{3}$ ). The slides were then reviewed by another experienced microscopist in an alternate city.

Venous blood was collected in sterile vacuum tubes with ethylenediaminetetraacetic acid (EDTA). Samples were centrifuged, and the sera were separated and stored at $-20^{\circ} \mathrm{C}$ until tested. In some cases, when the patient refused to have a venous blood sampling, digital blood from a finger prick was spotted onto FTA Micro Cards (Whatman, Clifton, NJ) and was prepared as recommended by the manufacturer using FTA Purification Reagent (Whatman). Blood samples were also examined using nested polymerase chain reaction (PCR)-based amplification of a species-specific segment of the $18 \mathrm{~S}$ rRNA gene of human malaria parasites, as described by Kimura et al. (1997), with modifications by Win et al. (2002). The DNA templates for PCR amplification were isolated from $200 \mu \mathrm{l}$ of whole blood (whenever available) using a MachereyNagel genomic DNA extraction kit for tissue (NucleoSpin Tissue).

\section{Clinical assessment}

Symptoms associated with malaria episodes were confirmed and assessed using microscopy and PCR, as described by da Silva-Nunes and Ferreira (2007) but with certain modifications. Patients were asked to complete a structured questionnaire addressing the following common symptoms: fever, chills, sweating, headache, myalgia, arthralgia, abdominal pain, nausea, vomiting, dizziness, cough, diarrhea, weakness, inappetence, bitter mouth, pallor, coryza, sneezing, and sore throat. Although not a symptom, pallor was also included in the questionnaire, because this is a common complaint in malaria patients and is sometimes mistakenly perceived to be a signal of jaundice by inexperienced health personal, since in 
174 Portuguese the word "yellow" is commonly used by patients to refer to anemia or to anemic

175 skin coloration. Patients were then asked if they noticed pallor at any time during their illness; if

176 they responded positively, the pallor was called a "symptom." The numerical scores of 0, 1, 2,

177 and 3 were assigned to symptoms reported to be absent, mild, moderate, or severe,

178 respectively. The author who conducted the interviews also assessed all infections to minimize

179 inter-observer variation. Patients perceived each clinical manifestation (except fever) as absent,

180 mild, moderate, or severe. Fever was classified as absent, mild, or severe. To minimize recall

181 bias and the possibility that the drug treatment might interfere with their symptoms, patients

182 were interviewed immediately after the diagnosis and before ingesting the first pills.

183 Treatment of malaria episodes

Patients were referred for treatment by authorized Ministry of Health workers, since, in

185 Brazil, the drug is dispensed only by these healthcare workers. Patients with vivax malaria were

186 treated with chloroquine and primaquine for 7 days, and those with falciparum malaria were

187 treated with a combined regimen of mefloquine, artesunate, and primaquine or with a

188 combination of artemether and lumefantrine (Coartem ${ }^{\circledR}$ ) whenever possible, according to

189 Brazil's current malaria therapy guidelines (Ministério da Saúde, 2010).

190 Statistical Analysis

191 Exploratory analysis

192 Data were entered using SPSS 13.0 software (SPSS Inc., Chicago, IL). Parasite loads were

193 stratified into two levels: (a) low parasitemia, $\leq 100$ parasites in 100 fields (roughly

194 corresponding to 1-300 parasites/ $\mu$ l of blood) and (b) moderate and high parasitemia, with > 
195100 parasites in 100 fields ( $>300$ parasites/ $\mu$ l of blood). Age was classified into $<14$ years and $\geq$

19614 years, in order to compare children and adolescents with adults. The number of previous

197 confirmed malaria episodes was divided per $\leq 8$ and $>8$ episodes, corresponding to the median

198 number of previous episodes experienced by the subjects included in the study. The duration of

199 symptoms in days was also divided per $\leq 3$ and $>3$ days, corresponding to the median number

200 of days during which symptoms were experienced. The distribution of the independent

201 variables was identified using the student's t-test to compare means and frequencies or

202 proportions were compared using the chi-square test, with $\alpha=0.05$. The Somers' D statistic

203 measure (Somers, 1962) was used to test for a dose-response relationship between symptom

204 scores and ordinal variables (level of parasitemia, age, duration of residence in Amazonia,

205 number of recent malaria episodes, and duration of symptoms prior to interview).

206 Multiple correspondence analysis

207 Correspondence analysis is an exploratory and descriptive statistical technique used in

208 analyzing data that are organized in contingency tables to verify associations or similarities

209 between qualitative or quantitative variables; these variables are categorized without a

210 probabilistic distribution defined a priori (Carvalho \& Struchiner, 1992; Greenacre \& Blasius,

211 2006). Multiple correspondence analyses facilitate the simultaneous examination of several

212 variables; the results are graphically represented, so that each category of every variable is

213 represented by a point, and the distance from one point to another represents the

214 relationships among the variables' categories (Carvalho \& Struchiner, 1992; Mota, Vasconcelos,

215 \& Assis, 2007). 
The multiple correspondence analysis was initiated using an ( $n \times p)$ matrix in which each

217 (n) line corresponds to a patient and each (p) column refers to a studied characteristic. Each 218 patient presents a $\left(p_{i}, i=1, \ldots, n\right)$ profile, defined by his/her characteristics; likewise, a $\left(p_{j}, j=\right.$

$2191, \ldots, p)$ profile can be drawn for each variable on the basis of the patients' answers (Greenacre 220 \& Blasius, 2006). Considering the $(n \times p)$ matrix as a set of $n$ points within a space of the $p$ dimension, the center of gravity within the mass of data corresponds to the mean value of all profiles and therefore can be identified as the profile expected value. The distances between each point and the center of gravity represent those between observed and expected values, which are called $\chi^{2}$ distances (Greenacre \& Blasius, 2006; Pereira, 2004). takes the value of zero when all data matrix points are superimposed on the center of gravity. The total inertia is decomposed as relative inertias pertaining to each evaluated dimension (Pereira, 2004; Paula et al, 2010). The square root of the inertia corresponds to an eigenvalue, which indicates the total amount of variability in the data that is explained by that dimension (Pereira, 2004).

The analysis of the absolute contribution of each category obtained through the inertia and the observation of the graph points for the correspondence analysis allow for the conceptual characterization of a graph's axis, also known as dimension. In turn, the relative contribution of a category measures how much of the variability of a given category is explained by the analyzed dimension (Mota, Vasconcelos, \& Assis, 2007). 
In the present study, it was expected that the graphical representation of the two

238

dimensions would illustrate the grouping areas of the categories of variables, which were included in the analysis on the frequency of malaria-related symptoms. This would allow the identification of symptoms that are grouped according to specific characteristics (age, gender, Plasmodium species, number of previous malaria episodes, and parasitemia).

To complement the interpretation of the results yielded by the multiple correspondence analysis, a dendrogram was designed to divide the data into similar groups on the basis of the coordinates' average (Maechler et al., 2015).

The statistical procedures were performed using the free R software environment, version 3.1.1 (The R Foundation for Statistical Computing, Vienna, Austria; http://www.rproject.org/), using the FactoMineR package (Husson, Josse, \& Mazet, 2014).

\section{Univariate logistic regression}

Univariate logistic regression analysis using R software version 3.1.1 was implemented to quantify the probability of experiencing each symptom on the basis of Plasmodium species, parasitemia, age, number of previous malaria episodes, and number of days during which symptoms were experienced.

\section{Ethical considerations}

This study was approved by the Ethics Committee for Research with Human Beings at the Federal University of Acre (protocol number 23107.016975/2011-28). Written informed consent was obtained from each participant or by his/her parent prior to the study.

\section{Results}


A total of 173 malaria cases were selected on the basis of a positive thick smear, indicating either $P$. vivax or $P$. falciparum. Samples from all patients were submitted for a molecular diagnosis, of which 171 cases revealed single-species malaria (137 cases of $P$. vivax and 34 cases of $P$. falciparum). Two cases, diagnosed as $P$. vivax based on a thick smear, reported a molecular diagnosis of mixed infection ( $P$. falciparum and $P$. vivax) and were therefore excluded from the analysis. ranged between 6 and 93 years (median $=26$ years, average $=29.3$ years). The majority of the people were born in the Amazon, and the average duration of residence in the area was 28.4 years. Only $3.03 \%$ of the participants did not have malaria prior to the study, and, for $7.88 \%$, the malaria episode experienced during the present study was their second occurrence. Almost $50 \%$ of the patients reported having at least eight malaria episodes prior to the study. Forty percent of the cases had patent, but low, parasitemia (lower than 200 parasites $/ \mathrm{mm}^{3}$ ); 39.40\% had parasitemia between 200 and 500 parasites $/ \mathrm{mm}^{3}$; and only two cases (1.20\%) had parasitemia higher than 10.000 parasites $/ \mathrm{mm}^{3}$ (Table 1). The median duration of symptoms was 3 days, while the mean was 5.33 days. The median duration of symptoms for each parasitemia strata was also 3 days.

Table 2 shows the frequency of each symptom, and Figure 1 shows the intensity of these symptoms. The most frequently experienced symptoms were headache (86.5\%), fever (78.4\%), and chills (75.4\%), while the least frequent was diarrhea (9.9\%). 
Multiple correspondence analysis and identification of symptom clusters

Figures $2 \mathrm{a}$ and $2 \mathrm{~b}$ show the joint distribution of the correspondence analysis

281

282

283 dimensions; three qualitative variables are included in the analysis: parasitemia, number of previous malaria episodes, and malaria species. The first two dimensions of the multiple correspondence analysis explained $20.3 \%$ and $11.4 \%$ of the total data variability, respectively. Symptoms are represented as "yes" and "no," indicating the influence of the presence of each symptom and the influence of the absence of each symptom. As depicted in Table 3 and Figures $2 a$ and $2 b$, it is possible to verify whether the following variable categories have an absolute contribution higher than $10 \%$ over dimension 1: fever, chills, sweating, headache, nausea, vomiting, abdominal pain, arthralgia, dizziness, myalgia, inappetence, weakness, and bitter mouth. The presence of these symptoms is graphically represented in the left lower quadrant, along the $\mathrm{x}$ axis. In dimension 2 , the categories that stood out were respiratory symptoms: cough, coryza, sneezing, sore throat, and diarrhea. They are graphically represented in the upper portion of the left upper quadrant, along the $y$ axis.

The visual interpretation of the combined representation of dimensions 1 and 2 in Figures $2 \mathrm{a}$ and $2 \mathrm{~b}$ and the output in Table 3 indicate that the subjects represented as blue dots in the left lower quadrant present most of the symptoms investigated; patients represented in the right lower quadrant do not show most of the symptoms investigated, and patients represented in the upper two quadrants tend to refer respiratory symptoms more often. The dendrogram (Figure 3) classifies the symptoms displayed in Figure 2a in five clusters, which are also represented in Figure $2 \mathrm{~b}$. The first cluster of symptoms (C1) includes fever-related symptoms and most of the algid symptoms (headache, chills, sweating, arthralgia, 
301 myalgia, weakness, and dizziness). The most frequently experienced symptoms were headache

302 (86.5\%), fever (78.4\%), and chills (75.4\%). Arthalgia (63.7\%), myalgia (64.3\%), and weakness

303 (62.6\%) were also frequent. Symptoms of this group occurred in up to $95.3 \%$ of the cases. The

304 second cluster of related symptoms (C2) comprised gastric symptoms (nausea, abdominal pain,

305 inappetence, and bitter mouth). They occurred in frequencies of $35.1-42.7 \%$, and $71.9 \%$

306 participants had at least one of these symptoms. Respiratory symptoms (from both the upper

307 and lower respiratory tracts) were clustered (C3). Coryza, sneezing, and sore throat were

308 reported in $18.1-22.2 \%$ of the cases, and cough was present in $24.0 \%$ of the patients.

309 Symptoms of this group occurred in up to $42.7 \%$ of the malaria cases. Diarrhea (C5) did not

310 cluster with any other symptom, and it occurred in $9.9 \%$ of the cases. Vomiting and pallor

311 constituted the fifth cluster of symptoms/signs (C4), with prevalences of $14.6 \%$ and $11.7 \%$,

312 respectively. Of all the symptoms, diarrhea, vomiting, and pallor were the three that occurred

313 least frequently.

314

Figure 4 shows the correspondence analysis result classified by the Plasmodium species, parasitemia, and the number of previous malaria episodes. The confidence ellipse delimitates the centroid around each variable. A visual examination of the joint distribution of the first two

317 dimensions revealed no difference in the median profile of vivax and falciparum malaria; that

318 is, the ellipses are superimposed. However, the symptom profile varies by the number of

319 parasitemia and that of previous malaria episodes. Patients with a higher parasitemia count ( $\geq$

320300 parasites $/ \mathrm{mm}^{3}$ ) have more symptoms (represented in the left side of dimension 1 ), and

321 those with a lower parasitemia count $\left(<300\right.$ parasites $\left./ \mathrm{mm}^{3}\right)$ tend to have fewer symptoms

322 (represented on the right-hand side of dimension 1). Finally, patients with more than eight 
323 previous malaria episodes generally experienced fewer symptoms, except for sore throat,

324 which was more pronounced in these patients.

325 Factors associated with the clinical and parasitological features of malaria

326 Using the Wald test for logistic regression (Table 4 and Figure 5), a higher parasitemia

327 count $\left(>300\right.$ parasites $\left./ \mathrm{mm}^{3}\right)$ was associated with the presence of fever $(\mathrm{OR}=5.4,95 \% \mathrm{Cl}=1.81$

$328-16.12, \mathrm{P}=0.003)$, vomiting $(\mathrm{OR}=2.51,95 \% \mathrm{Cl} 1.06-5.94, \mathrm{P}=0.036)$, dizziness $(\mathrm{OR}=2.21$,

$32995 \% \mathrm{Cl} 1.14-4.26, \mathrm{P}=0.018)$, and weakness $(\mathrm{OR}=2.74,95 \% \mathrm{Cl}=1.33-5.63, \mathrm{P}=0.006) . \mathrm{A}$

330 higher parasitemia count, however, was not associated with other symptoms. The occurrence

331 of arthralgia $(\mathrm{OR}=5.44,95 \% \mathrm{Cl}=2.37-12.52, \mathrm{P}<0.001)$ and myalgia $(\mathrm{OR}=5.64,95 \% \mathrm{Cl}=2.45$

$332-12.99, \mathrm{P}<0.001$ ) was associated with age, being more likely to occur in patients older than 14

333 years. Having experienced at least eight malaria episodes prior to the study was associated with

334 a decreased risk of fever $(\mathrm{OR}=0.30,95 \% \mathrm{Cl} 0.18-0.84, \mathrm{P}=0.017)$ and chills $(\mathrm{OR}=0.44,95 \% \mathrm{Cl}$

$3350.21-0.91, \mathrm{P}=0.027)$ and with an increased risk of sore throat $(\mathrm{OR}=2.36,95 \% \mathrm{Cl}=1.1-5.04, \mathrm{P}=$

336 0.027). None of the symptoms showed an association with gender, Plasmodium species, or

337 duration of symptoms.

338 Severe headache, myalgia, chills, and fever were observed in more than one third of the

339 cases, but all the other symptoms were mild or moderate (Figure 1). There was no association

340 between symptom intensity and gender or malaria species.

341 The intensity of chills, fever, and sweating was associated with the number of previous

342 episodes of malaria, and patients who had experienced more than eight episodes of malaria

343 had less intense symptoms $(P<0.005)$. A higher parasitemia count was associated with more 
344 intense fever $(P<0.001)$, while myalgia was more intense in patients over the age of 14 years ( $P$ $345<0.001)$ (Figure 5).

346 When analyzing the intensity of symptoms with the duration of symptoms, there were

347 associations with chills, fever, sweating $(P=0.002)$, headache $(P<0.001)$, nausea $(P<0.001)$,

348 abdominal pain $(P<0.001)$, diarrhea $(P<0.008)$, and arthralgia $(P=0.032)$, which tended to be

349 more intense in patients with shorter durations of illness than in those experiencing the disease

350 for more than 3 days.

\section{Discussion}

Malaria is a clinical condition that generates several symptoms. This study performed a

353

354

hierarchical analysis that grouped these symptoms into five clusters. Two of the clusters combine the most common symptoms observed in nonsevere malaria (the cluster of algic and fever-related symptoms and the cluster of gastric-related symptoms). These symptoms have been widely reported in many clinical and experimental studies. The remaining three clusters focus on respiratory symptoms and diarrhea, vomiting, and pallor.

In this study, headache was the most frequent symptom, a finding that has been reported in previous studies of African children (Roestenberg et al., 2012) and pregnant women (Tahita et al., 2013) with malaria. Fever and related symptoms (chills and sweating) were also frequently observed. However, fever was less likely to occur in patients with a history of multiple malaria episodes and a low parasitemia count.

The analysis of symptom intensity showed that a higher parasitemia count is associated with higher fever, and a lower parasitemia count is associated with mild fever or, sometimes, 
365 an absence of fever. Studies have reported a relationship between parasitemia and symptom

366 intensity (da Silva-Nunes \& Ferreira, 2007; Torres et al., 2014). The lack of fever can hinder

367 healthcare delivery because, more often than not, an active malaria diagnosis is fever-oriented

368 [28]. Also, symptoms tended to be more intense in the first days of illness, probably because of

369 the semi-immune status of the patients who had previously experienced episodes of malaria.

370 Thus, healthcare workers in endemic areas must receive formal training on the clinical

371 spectrum of malaria, including nonsevere malaria without fever, and on the heterogeneity of

372 symptoms during illness.

Arthalgia and myalgia were common and were more likely to occur in patients over the age of 14 years. Other studies (da Silva-Nunes \& Ferreira, 2007; Chandramohan et al., 2001) have confirmed this finding and have revealed a higher susceptibility to skeletal pain in older individuals.

Respiratory symptoms associated with nonsevere malaria have been reported for vivax malaria. In a study of 15 adults with uncomplicated vivax malaria, a total of $40 \%$ reported limited dry cough (Anstey et al., 2002). Flu-like symptoms such as coryza and sneezing have also been observed. However, it is difficult to distinguish between malaria flu-like symptoms and influenza. Experimental malaria studies have shown that flu-like symptoms in malaria can be easily classified as flu itself (Lillie et al., 2012). Thus, it must be underscored that flu-like symptoms can be observed in cases of malaria, and in areas where malaria transmission is present, testing for malaria is important in patients presenting with flu-like symptoms at health-centres. 

studies (He et al., 2013; Luxemburger et al., 1998). While some have found gastric symptoms to be effective predictors of malaria, especially in falciparum malaria (He et al., 2013), others have found them to be infrequent (Luxemburger et al., 1998). However, these studies tend to group nausea, diarrhea, and vomiting. The hierarchical clustering analysis performed in the present study showed that while the majority of gastric symptoms are experienced at the same time, diarrhea and vomiting form a separate cluster of symptoms and are not related to nausea and other minor gastric symptoms. This is a novel finding, but the reasons for that are unclear. of African children with malaria (Vinnemeier et al., 2012). In some studies, vomiting was associated with falciparum malaria, but this can be a result of the higher parasitemia count caused by $P$. falciparum, because these cases had a much higher parasite load (Luxemburger et al., 1998). Although no relationship between vomiting and the Plasmodium species was found, an association between vomiting and a higher parasitemia count was observed. Diarrhea was infrequent in semi-immune patients and was more closely related to vomiting and pallor than to any other symptom. In nonimmune patients, an increased prevalence of diarrhea may occur. Taylor et al. (2010) found a $21 \%$ prevalence in the meta 405 analyses of malaria cases of travelers returning from endemic areas for malaria. For military personnel working in endemic areas, diarrhea was reported to be at a $50 \%$ prevalence (He et 
409

410 411 (Vinnemeier et al., 2012).

412

413

414

415

416

417

418

419

420

421

422

423

424

425

426

427

428 become less pronounced.

diarrhea can be related to parasitemia and/or to acquired immunity. In areas where other febrile illnesses co-exist, diarrhea can be frequent but have low specificity for malaria

Nausea, inappetence, bitter mouth, and abdominal pain were relatively frequent (up to 68.5\%); however, few studies have cited them as frequent symptoms. Mutanda et al. (2014) reported inappetence in children as an effective predictor of malaria. An examination of these discrete gastric symptoms can help to assess malaria in specific groups, such as children, or to provide a more detailed evaluation of vaccine efficacy. Bitter mouth and nausea can be an organism's natural defense against toxic substances (Peyrot des Gachons et al., 2011) and response to malarial toxins (Haldar \& Mohndas, 2009; Hiller et al., 2004).

In the present study, both the frequency and intensity of certain symptoms varied by past exposure to malaria. The higher the number of previous malaria episodes, the less intense the presentation of certain symptoms, such as fever, chills, and sweating. The data suggest that previous episodes confer some amount of clinical immunity, and symptoms can therefore

The quantification of symptoms in nonsevere malaria is of increasing importance, given that several vaccines are being tested on human subjects. These vaccines may reduce the intensity of symptoms, and thus the optimization of an algorithm to assess symptoms can provide better estimates of vaccine efficacy, especially in the case of developing a vaccine for $P$. vivax (Arévalo-Herrera et al., 2014). 
Nevertheless, this study has certain limitations. We were unable to identify symptoms

430

431

432

that could differentiate noncomplicated vivax and falciparum malaria, although a limited number of $P$. falciparum cases were assessed. However, Luxemburger et al. (1998) conducted a study in Thailand using a larger dataset and did not find differences in symptoms between the two species. McKenzie et al. (2006) revealed that falciparum malaria showed higher incidence rate of fever than vivax malaria; however, this was related to the parasitemia levels. In areas where $P$. vivax and $P$. falciparum co-exist, the clinical pictures may overlap, making it impossible to differentiate between the two parasites without diagnostic tests.

\section{Conclusion}

Malaria is a complex disease that presents with multiple symptoms. The nonsevere form features a broad range of symptoms that can be grouped into clusters, with some symptoms appearing more frequently than others. The existence and intensity of symptoms are related to the patient's age, as well as to parasitemia level and exposure to the Plasmodium species. This information is important for healthcare workers in endemic areas who perform both passive and active diagnoses. In addition, a complete assessment of malaria-related symptoms is useful for the diagnosis of malaria in travelers returning to nonendemic areas. The evaluation of effects of the parasite-host relationship on clinical presentation can be useful for studies assessing immunological response and the development of vaccines aimed at decreasing symptom severity. New statistical techniques, such as multiple correspondence analysis, as shown in this study, can help to identify groups of patients with similar clinical presentation according to variables of interest, in malaria studies as well as in studies of other diseases. 


\section{LIST OF ABBREVIATIONS}

452

Symptoms abbreviations are as follows: headache: Hea, fever: Fev, chills: Chi, myalgia: Mya, arthralgia: Art, weakness: Wea, sweating: Swe, dizziness: Diz, nausea: Nau, bitter mouth: Bit, inappetence: Ina, abdominal pain: Abd, cough: Cou, Coryza: Cor, sore throat: Sor, sneezing: Sne, pallor: Pal, diarrhoea: Dia.

456

The authors declare they have no competing interest.

AUTHOR CONTRIBUTIONS

MdaSN and ACM planned the study. ACM, FMA, CBB, RN, RAA and MGSG searched for malaria cases in

healthcare units, performed thick blood smear tests and tabulated data. ACM conducted clinical interviews, with the supervision of MdaSN. RSM, LNF and LRC performed the molecular studies. ACM and MdaSN performed exploratory and logistic regression analysis. MdaSN, CTC and OGC performed the multiple correspondence analysis. ACM and MdaSN wrote the manuscript. All other authors revised the manuscript and contributed to the discussion of the results and revision of the intellectual content in the research. All authors approve the final version of the manuscript.

\section{ACKNOWLEDGEMENTS}

470

We thank the population and the local-health and government authorities for their help.

472

473

474 


\section{References}

477

478

479

480

481

482

483

484

485

486

487

488

489

490

491

492

493

494

495

496

497

498

499

500

501

502

503

504

505

506

507

Acre. Governo do Estado do Acre. State Program of Ecological-Economical Assessment of State of Acre. Phase II: Synthesis document. 2nd edition. 1:250.000 scale. Rio Branco, 2010. 358 p.

Anstey NM, Jacups SP, Cain T, Pearson T, Ziesing PJ, Fisher DA, Currie BJ, Marks PJ, Maguire GP. 2002. Pulmonary manifestations of uncomplicated falciparum and vivax malaria: cough, small airways obstruction, impaired gas transfer, and increased pulmonary phagocytic activity. Journal of Infectios Diseases 185:1326-34.

Ansumana R, Jacobsen KH, Gbakima AA, Hodges MH, Lamin JM, Leski TA, Malanoski AP, Lin B, Bockarie MJ, Stenger DA. 2013. Presumptive self-diagnosis of malaria and other febrile illnesses in Sierra Leone. Pan African Medical Journal 15:34.

Carvalho MS, Struchiner CJ. 1992. Análise de correspondência: uma aplicação do método à avaliação de serviços de vacinação. Cadernos de Saúde Pública 8:287-301.

Chandramohan D, Carneiro I, Kavishwar A, Brugha R, Desai V, Greenwood B 2001. A clinical algorithm for the diagnosis of malaria: results of an evaluation in an area of low endemicity. Tropical Medicine \& International Health 7:505-510.

Cifuentes SG, Trostle J, Trueba G, Milbrath M, Baldeón ME, Coloma J, Eisenberg JN. 2013. Transition in the cause of fever from malaria to dengue, Northwestern Ecuador, 1990-2011. Emerging Infection Diseases 10:1642-1645.

da Silva-Nunes M, Ferreira MU. 2007. Clinical spectrum of uncomplicated malaria in semiimmune Amazonians: beyond the " symptomatic " vs " asymptomatic " dichotomy. Memorias do Instituto Oswaldo Cruz 102:341-347.

da Silva-Nunes M, Moreno M, Conn JE, Gamboa D, Abeles S, Vinetz JM, Ferreira UM. 2012 Amazonian malaria: asymptomatic human reservoirs, diagnostic challenges, environmentally driven changes in mosquito vector populations, and the mandate for sustainable control strategies. Acta Tropica 121:281-291.

Dos-Santos JC, Angerami RN, Castiñeiras CM, Lopes SC, Albrecht L, Garcia MT, Levy CE, Moretti ML, Lacerda MV, Costa FT. 2014. Imported malaria in a non-endemic area: the experience of the university of Campinas hospital in the Brazilian Southeast. Malaria Journal 13:280.

Greenacre MJ, Blasius J. 2006. Multiple correspondence analysis and related methods. London: Chapman \& Hall 
Haldar K, Mohandas N. 2009. Malaria, erythrocytic infection, and anemia. Hematology American Society of Hematology Education Program 2:87-93.

- He D, Zhang Y, Liu X, Guo S, Zhao D, Zhu Y, Li H, Kong L. 2013. Epidemiological and clinical features of Plasmodium falciparum malaria in united nations personnel in WesternBahr el Ghazal State, South Sudan. PLoS One 8:e55220.

Hiller NL, Bhattacharjee S, van Ooij C, Liolios K, Harrison T, Lopez-Estraño C, Haldar K. 2004. A host-targeting signal in virulence proteins reveals a secretome in malarial infection. Science 306:1934-1937.

Husson F, Josse J, Le S, Mazet J. FactoMineR: Multivariate exploratory data analysis and data mining with R. $R$ package version 1.27. Available at: http://CRAN.Rproject.org/package=FactoMineR. (accessed 10 August 2014).

Instituto Brasileiro de Geografia e Estatística. 2010 Population Census: Synopsis Acre, Mâncio Lima. Available at:

http://www.cidades.ibge.gov.br/xtras/temas.php?lang=\&codmun=120033\&idtema=1\&search= acre|mancio-lima|censo-demografico-2010:-sinopse-. [accessed 13 March 2012].

Kimura M, Kaneko O, Liu Q, Zhou M, Kawamoto F, Wataya Y, Otani S, Yamaguchi Y, Tanabe K. 1997. Identification of the four species of human malaria parasites by nested PCR that targets variant sequences in the small subunit rRNA gene. Parasitoly International 46:91-95.

Lillie PJ, Duncan CJ, Sheehy SH, Meyer J, O'Hara GA, Gilbert SC, Hill AV. 2012. Distinguishing malaria and influenza: early clinical features in controlled human experimental infection studies. Travel Medicine and Infectious Diseases 4:192-196

López-Vélez R, Viana A, Pérez-Casas C, Martín-Aresti J, Turrientes MC, García-Camacho A. 1999. Clinicoepidemiological study of imported malaria in travelers and immigrants to Madrid. Journal of Travel Medicine 6:81-86.

Lüthi B, Schlagenhauf P. 2015. Risk factors associated with malaria deaths in travellers: A literature review. Travel Medicine and Infectious Diseases 13:48-60. doi: 10.1016/j.tmaid.2014.04.014.

Luxemburger C, Nosten F, Kyle DE, Kiricharoen L, Chongsuphajaisiddhi T, White NJ. 1998. Clinical features cannot predict a diagnosis of malaria or differentiate the infecting species in children living in an area of low transmission. Transactions of Royal Society of Tropical Medicine and Hygiene 1:45-49.

Maechler M, Rousseeuw P, Struyf A, Hubert M. Cluster analysis basics and extensions. Available at: http://CRAN.R-project.org/package=cluster (accessed 10 August 2014). 
McKenzie FE, Smith DL, O'Meara WP, Forney JR, Magill AJ, Permpanich B, Erhart LM, Sirichaisinthop J, Wongsrichanalai C, Gasser RA Jr. 2006. Fever in patients with mixed-species malaria. Clinical Infectious Diseases 42:1713-1718.

Matangila JR, Lufuluabo J, Ibalanky AL, Inocêncio da Luz RA, Lutumba P, Van Geertruyden JP. 2014. Asymptomatic Plasmodium falciparum infection is associated with anaemia in pregnancy and can be more cost-effectively detected by rapid diagnostic test than by microscopy in Kinshasa, Democratic Republic of the Congo. Malaria Journal 13:132.

Ministério da Saúde. Manual de Diagnóstico Laboratorial da Malária. Volume 1, 1st Edition. [Handbook of Laboratory Diagnosis of Malaria]. Edited by Ministério da Saúde. Brasil: 2005:5761.

Ministério da Saúde. 2015. SIVEP - Malária - Sistema de informações de vigilância epidemiológica - notificação de casos Available at: http://portalweb04.saude.gov.br/sivep malaria/default.asp. (acessed 13 March 2015).

Ministério da saúde. 2010. Guia prático de tratamento da malária no Brasil. Brasília: Ministério da Saúde, 15-25.

Mota JC, Vasconcelos AGG, Assis SG. 2007. Análise de correspondência como estratégia para descrição do perfil da mulher vítima do parceiro atendida em serviço especializado. Ciências $e$ Saúde Coletiva 12:799-809.

Mutanda AL, Cheruiyot P, Hodges JS, Ayodo G, Odero W, John CC. 2014. Sensitivity of fever for diagnosis of clinical malaria in a Kenyan area of unstable, low malaria transmission. Malaria Journal 13:163.

O'Brien AT, Ramírez JF, Martínez SP. 2014. A descriptive study of 16 severe Plasmodium vivax cases from three municipalities of Colombia between 2009 and 2013. Malaria Journal 13:404.

Okell LC, Bousema T, Griffin JT, Ouédraogo AL, Ghani AC, Drakeley CJ. 2012. Factors determining the occurrence of submicroscopic malaria infections and their relevance for control. Nat Communications 3:1237. doi: 10.1038/ncomms2241.

Paula FL, Fonseca MJM, Oliveira RVC, Rozenfeld S. 2010. Perfil de idosos com internação por quedas nos hospitais públicos de Niterói (RJ). Revista Brasileira de Epidemiologia 13:587-595.

Pereira JCR. 2004. Análise de dados qualitativos: estratégias metodológicas para as ciências da saúde, humanas e sociais. São Paulo: EDUSP, 156. 
Périssé AR, Strickland GT. 2008. Usefulness of clinical algorithm as screening process to detected malaria in low-to-moderate transmission areas of scarce health related resources. Acta Tropica 107:224-229.

Peyrot des Gachons C, Beauchamp GK, Stern RM, Koch KL, Breslin PA. 2011. Bitter taste induces nausea. Current Biology 21:247-248.

Roestenberg M, O'Hara GA, Duncan CJ, Epstein JE, Edwards NJ, Scholzen A, van der Ven AJ, Hermsen CC, Hill AV, Sauerwein RW. 2012. Comparison of clinical and parasitological data from controlled human malaria infection trials. Plos one 7:e38434.

Somers RH. 1962. A new asymmetric measure of association for ordinal variables. American Sociological Review 27: 799-811.

Tahita MC, Tinto H, Menten J, Ouedraogo JB, Guiguemde RT, van Geertruyden JP, Erhart A, D'Alessandro U. 2013. Clinical signs and symptoms cannot reliably predict Plasmodium falciparum malaria infection in pregnant women living in an area of high seasonal transmission. Malaria Journal 12:464.

Taylor SM, Molyneux ME, Simel DL, Meshnick SR, Juliano JJ. 2010. Does this patient have malaria? JAMA 304:2048-2056.

Torres KJ, Villasis E, Bendezú J, Chauca J, Vinetz JM, Gamboa D. 2014. Relationship of regulatory T cells to Plasmodium falciparum malaria symptomatology in a hypoendemic region. Malaria Journal 13:108.

Vinnemeier CD, Schwarz NG, Sarpong N, Loag W, Acquah S, Nkrumah B, Huenger F, Adu-Sarkodie $\mathrm{Y}$, May J. 2012. Predictive value of fever and palmar pallor for P. falciparum parasitaemia in children from an endemic area. PLoS One 7:e36678.

Win TT, Lin K, Mizuno S, Zou M, Liu Q, Ferreira MU, Tantular IS, Kojima S, Ishii A, Kawamoto F. 2002. Wide distribution of Plasmodium ovale in Myanmar. Tropical Medicine \& International Health 7:231-239. 
611

612

613

614

615

616

617

PeerJ reviewing PDF | (2015:07:5751:1:1:NEW 23 Sep 2015) 
618

619

620 Table 1 - Epidemiological and parasitological characteristics of malaria cases, Mancio Lima, 2012-2013.

\begin{tabular}{lll}
\hline Variables & $\mathrm{n}$ & $\%$ \\
\hline Gender & & \\
Female & 76 & 44.4 \\
Male & 95 & 55.6
\end{tabular}

\section{Type of malaria}

P. vivax

80.10

P. falciparum

34

19.10

\section{Parasitemia}

$<200$ parasites $/ \mathrm{mm}^{3}$

$68 \quad 40.00$

$200-300$ parasites $/ \mathrm{mm}^{3}$

$44 \quad 25.90$

301 - 500 parasites $/ \mathrm{mm}^{3}$

23

13.50

501- 10.000 parasites $/ \mathrm{mm}^{3}$

33

19.40

10.001-100.000 parasites $/ \mathrm{mm}^{3}$

2

1.20

Number of previous malaria episodes

None

$\begin{array}{ll}5 & 3.03\end{array}$

Only one malaria episode

13

7.88

Between 2 and 7 malaria episodes

$66 \quad 40.00$

More or equal to 8 malaria episodes

81

49.09

621

622

623

624

625

626

627

628

629

630 
Table 2 - Frequency of 19 symptoms related to malaria, Mancio Lima, 2012-2013.

\begin{tabular}{|c|c|c|c|c|}
\hline $\begin{array}{l}\text { Group of } \\
\text { symptoms }\end{array}$ & Symptom & $\begin{array}{l}\text { P.v } \\
\text { n (\%) }\end{array}$ & $\begin{array}{l}\text { P.f } \\
\text { n (\%) }\end{array}$ & $\begin{array}{l}\text { P. v + P.f } \\
n(\%)\end{array}$ \\
\hline \multirow{9}{*}{$\begin{array}{l}\text { Algic and } \\
\text { fever-related } \\
\text { symptoms }\end{array}$} & Headache & 119 (86.9) & $29(85.3)$ & 148 (86.5) \\
\hline & Fever & $110(80.3)$ & $24(70.6)$ & $134(78.4)$ \\
\hline & Chills & 104 (75.9) & $25(73.5)$ & $129(75.4)$ \\
\hline & Myalgia & $86(62.8)$ & $24(70.6)$ & $110(64.3)$ \\
\hline & Arthralgia & $85(62.0)$ & $24(70.6)$ & 109 (63.7) \\
\hline & Weakness & $88(64.2)$ & 19 (55.9) & 107 (62.6) \\
\hline & Sweating & 75 (54.7) & 19 (55.9) & 94 (55.0) \\
\hline & Dizziness & 67 (48.9) & $22(64.7)$ & $89(52.0)$ \\
\hline & Any symptom & 131 (95.6) & $32(94.1)$ & 163 (95.3) \\
\hline \multirow{5}{*}{$\begin{array}{l}\text { Gastric } \\
\text { symptoms }\end{array}$} & Nausea & $57(41.6)$ & $16(47.1)$ & $73(42.7)$ \\
\hline & Bitter mouth & $48(35.0)$ & $16(47.1)$ & $64(37.4)$ \\
\hline & Inapetence & $48(35.0)$ & $15(44.1)$ & $63(36.8)$ \\
\hline & Abdominal pain & $46(33.6)$ & $14(41.2)$ & $60(35.1)$ \\
\hline & Any symptom & $94(68.5)$ & $29(85.3)$ & 123 (71.9) \\
\hline \multirow{5}{*}{$\begin{array}{l}\text { Respiratory } \\
\text { symptoms }\end{array}$} & Cough & $32(23.4)$ & $9(26.5)$ & $41(24)$ \\
\hline & Coryza & $33(24.1)$ & $5(14.7)$ & $38(22.2)$ \\
\hline & Sore throat & $33(24.1)$ & $3(8.8)$ & $36(21.1)$ \\
\hline & Sneeze & $26(19.0)$ & $5(14.7)$ & 31 (18.1) \\
\hline & Any symptom & 61 (44.5) & $12(35.3)$ & 73 (42.7) \\
\hline \multirow{3}{*}{$\begin{array}{l}\text { Vomiting and } \\
\text { pallor }\end{array}$} & Vomiting & 19 (13.9) & $6(17.6)$ & $25(14.6)$ \\
\hline & Pallor & $14(10.2)$ & $6(17.6)$ & $20(11.7)$ \\
\hline & Any symptom & $29(21.2)$ & $8(23.5)$ & 37 (21.6) \\
\hline
\end{tabular}




\begin{tabular}{lllll}
\hline Diarrhea & Diarrhea & $11(8.0)$ & $6(17.6)$ & $17(9.9)$ \\
\hline
\end{tabular}

632

633

634

635

636

637

638

639

640

641

642

643

644

645

646

647

648

649

650

651

652 
653 Table 3 - Relative contributions of the first and second dimensions of the correspondence analysis and $\mathrm{R}^{2}$ values 654 according to symptoms, Mancio Lima, 2012-2013.

\begin{tabular}{|c|c|c|c|c|c|c|c|}
\hline $\begin{array}{l}\text { Group of } \\
\text { symptoms }\end{array}$ & Symptom & $\begin{array}{l}\text { Dimension } \\
1\end{array}$ & $\begin{array}{l}\text { Dimension } \\
2\end{array}$ & $\begin{array}{l}R^{2} \\
\text { Dimension } \\
1 \\
\end{array}$ & $\begin{array}{l}\mathrm{P} \text { value } \\
1\end{array}$ & $\begin{array}{l}\mathbf{R}^{2} \\
\text { Dimension } \\
2 \\
\end{array}$ & $\begin{array}{l}P \\
\text { value } 2\end{array}$ \\
\hline \multirow{8}{*}{$\begin{array}{l}\text { Algic and } \\
\text { fever- } \\
\text { related } \\
\text { symptoms }\end{array}$} & Headache & 0.279 & 0.016 & 0.279 & $<0.001$ & \multirow{4}{*}{0.026} & \multirow{4}{*}{0.04} \\
\hline & Fever & 0.409 & 0.005 & 0.409 & $<0.001$ & & \\
\hline & Chills & 0.370 & 0.026 & 0.370 & $<0.001$ & & \\
\hline & Myalgia & 0.273 & 0.003 & 0.273 & $<0.001$ & & \\
\hline & Arthralgia & 0.274 & 0.052 & 0.274 & $<0.001$ & \multirow[t]{3}{*}{0.052} & \multirow[t]{3}{*}{0.003} \\
\hline & Weakness & 0.305 & 0.007 & 0.305 & $<0.001$ & & \\
\hline & Sweating & 0.160 & 0.002 & 0.160 & $<0.001$ & & \\
\hline & Dizziness & 0.329 & 0.035 & 0.329 & $<0.001$ & 0.035 & 0.016 \\
\hline \multirow{4}{*}{$\begin{array}{l}\text { Gastric } \\
\text { symptoms }\end{array}$} & Nausea & 0.284 & 0.001 & 0.284 & $<0.001$ & & \\
\hline & Bitter mouth & 0.317 & 0.001 & 0.317 & $<0.001$ & & \\
\hline & Inapetence & 0.291 & 0.001 & 0.291 & $<0.001$ & & \\
\hline & $\begin{array}{l}\text { Abdominal } \\
\text { pain }\end{array}$ & 0.153 & 0.027 & 0.153 & $<0.001$ & 0.027 & 0.035 \\
\hline \multirow{4}{*}{$\begin{array}{l}\text { Respiratory } \\
\text { symptoms }\end{array}$} & Cough & 0.046 & 0.443 & \multirow[t]{4}{*}{0.046} & 0.006 & 0.443 & $<0.001$ \\
\hline & Coryza & 0.003 & 0.495 & & $<0.001$ & 0.443 & $<0.001$ \\
\hline & Sore throat & 0.001 & 0.461 & & $<0.001$ & 0.461 & $<0.001$ \\
\hline & Sneeze & 0.009 & 0.511 & & & 0.511 & $<0.001$ \\
\hline \multirow{2}{*}{$\begin{array}{l}\text { Vomiting } \\
\text { and pallor }\end{array}$} & Vomiting & 0.161 & 0.006 & & 0.161 & & \\
\hline & Pallor & 0.123 & 0.001 & & 0.123 & & \\
\hline Diarrhea & Diarrhea & 0.033 & 0.100 & & 0.033 & 0.100 & $<0.001$ \\
\hline
\end{tabular}

655

656

657 
659 Table 4 - Association between symptoms and clinical features in malaria cases, Mancio Lima, 2012-2013

660

661

Outcome: Parasitemia higher than 300 parasites $/ \mathrm{mm}^{3}$

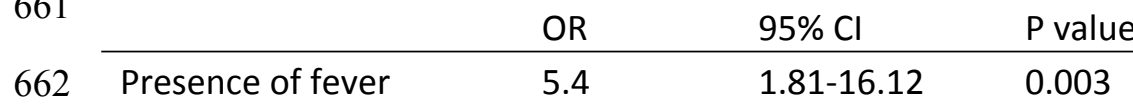

663

Presence of vomiting

2.51

1.06-5.94

0.036

664

Presence of dizziness

2.21

$1.14-4.26$

0.018

665

Presence of weakness

2.74

$1.33-5.63$

0.006

666

\begin{tabular}{|c|c|c|c|}
\hline \multicolumn{4}{|c|}{ Outcome: Age older than 14 years old } \\
\hline & OR & $95 \% \mathrm{Cl}$ & $P$ value \\
\hline Presence of arthralgia & 5.44 & $2.37-12.52$ & $<0.001$ \\
\hline Presence of myalgia & 5.64 & $2.45-12.99$ & $<0.001$ \\
\hline
\end{tabular}

670

Outcome: Number of previous malaria equal or higher than 8

671

672

\begin{tabular}{llll}
\hline & OR & $95 \% \mathrm{Cl}$ & P value \\
\hline Presence of fever & 0.3 & $0.18-0.84$ & 0.017
\end{tabular}

673

Presence of chills

0.44

0.21-0.91

0.027

674

Presence of sore throat

2.36

1.1-5.04

0.027

675

676

677

678

679

680

681 
Figure 1 - Frequency and intensity of each malaria-related symptom in Mancio Lima (20122013). Numbers on y axis are percentages. The shading pattern of each bar indicates the proportion of patients reporting a given symptom as absent, mild, moderate or severe. $\mathrm{C} 1=$ Algic and fever-related symptoms; $\mathrm{C} 2$ = Gastric symptoms; $\mathrm{C} 3$ = Respiratory symptoms; $\mathrm{C} 4$ = Vomiting and pallor; C5 = Diarrhoea.

690

Figure $2-(A)$ Joint distribution of the correspondence analysis dimensions for qualitative variables (parasitemia, number of previous malaria episodes and malaria species). Dimension 1 and 2 contribute to explain $31.74 \%$ of the variance. The contribution of each symptom in dimension 1 and 2 is represented as a triangle, where 'yes' indicates the contribution of the presence of the symptom, and 'no' indicates the contribution of the absence of the symptom. Subjects are represented as blue dots, and their position in each quadrant demonstrate the referred symptom profile of each individual (near the presence of symptoms or near the absence of symptoms). (B) Joint distribution of the correspondence analysis dimensions for qualitative variables (parasitemia, number of previous malaria episodes and malaria species) with circles indicating groups of symptoms identified in the cluster analysis. C1 = Algic and fever-related symptoms; $\mathrm{C} 2$ = Gastric symptoms; $\mathrm{C} 3$ = Respiratory symptoms; $\mathrm{C} 4$ = Vomiting and pallor; $\mathrm{C} 5$ = Diarrhoea.

Figure 3 - Dendrogram of the coordinates of the first two dimensions of the correspondence analysis with clusters of groups. C1 = Algic and fever-related symptoms; C2 = Gastric symptoms; C3 = Respiratory symptoms; C4 = Vomiting and pallor; C5 = Diarrhoea. 
Figure 4 - Multiple correspondence analysis classified by Plasmodium species, parasitemia

709

710

711

712

713

714

715

716

717

718

719

720

721

722

723

724

725

726

727

728

729

730

731

732

733

734 and number of previous malaria episodes. The confidence ellipse delimitates the centroid around each variable. For Parasitemia, ellipses are separated, indicating a good distinction in symptom profile between low and high parasitemia. Patients with higher parasitemia ( $\geq 300$ parasites $/ \mathrm{mm}^{3}$ ) have more symptoms (pink ellipse is seen in the left-hand side of dimension 1) and those with lower parasitemia $\left(<300\right.$ parasites $/ \mathrm{mm}^{3}$ ) tend to have fewer symptoms (blue ellipse represented on the right-hand side of dimension 1). For Plasmodium species, ellipses are superimposed, indicating that the symptom profile shown in each type of malaria is very similar, and therefore malaria species cannot be differentiated using symptoms only. For number of previous episodes of malaria, there is little superimposition of the ellipses, indicating that it is possible to separate between those patients with more than eight previous malaria episodes, who generally experience fewer symptoms (pink ellipse is in the right side of Dimension 1, indicating less symptoms), except for symptoms sore throat, which is more pronounced in these patients (note that the pink ellipse is above the blue ellipse in Dimension 2, indicating that symptoms distributed along dimension 2 are differentiating patients with 8 or more episodes from those with less than 8 episodes).

Figure 5 -- Relationship between symptom intensity and parasitological features (number of previous malaria episodes, parasitemia and age) in Mancio Lima (2012-2013). Numbers on y axis are percentages. The shading pattern of each bar segment indicates the proportion of patients reporting a given symptom as absent, mild, moderate or severe. $\mathrm{P}$ value $=$ Somers' $\mathrm{d}$ test for ordinal variables 
Figure 1

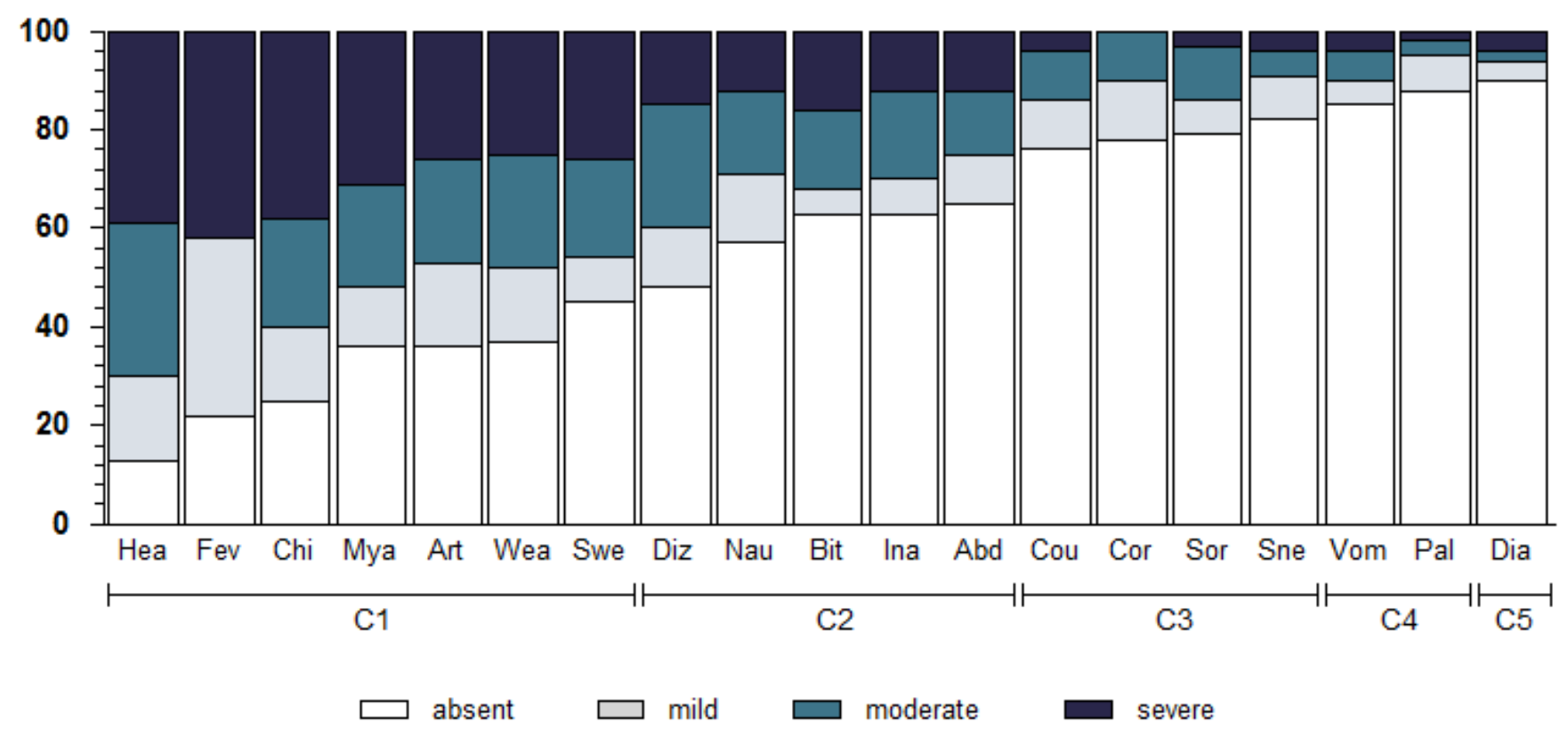




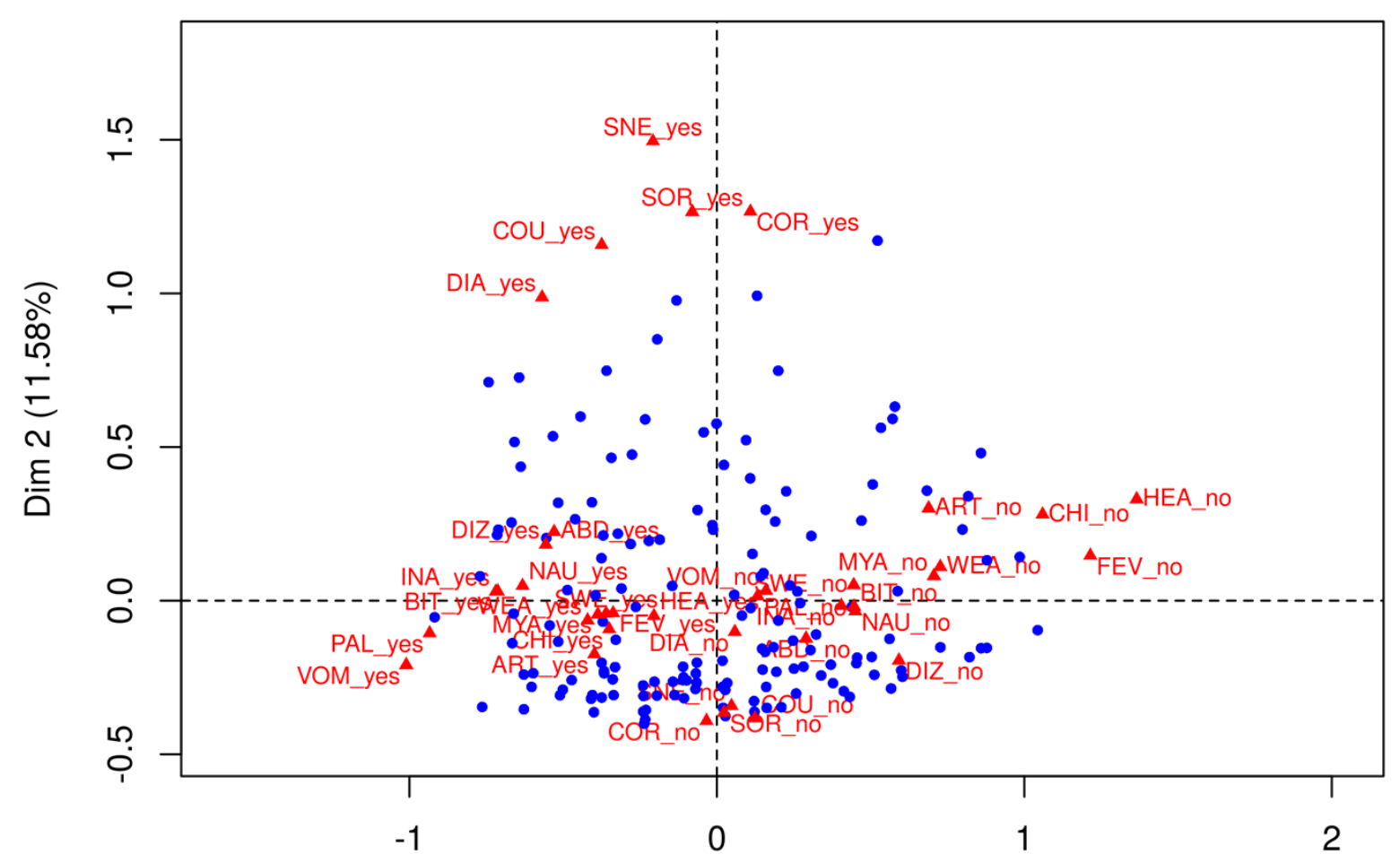

$\operatorname{Dim} 1(20.16 \%)$ 
756 Figure 2b

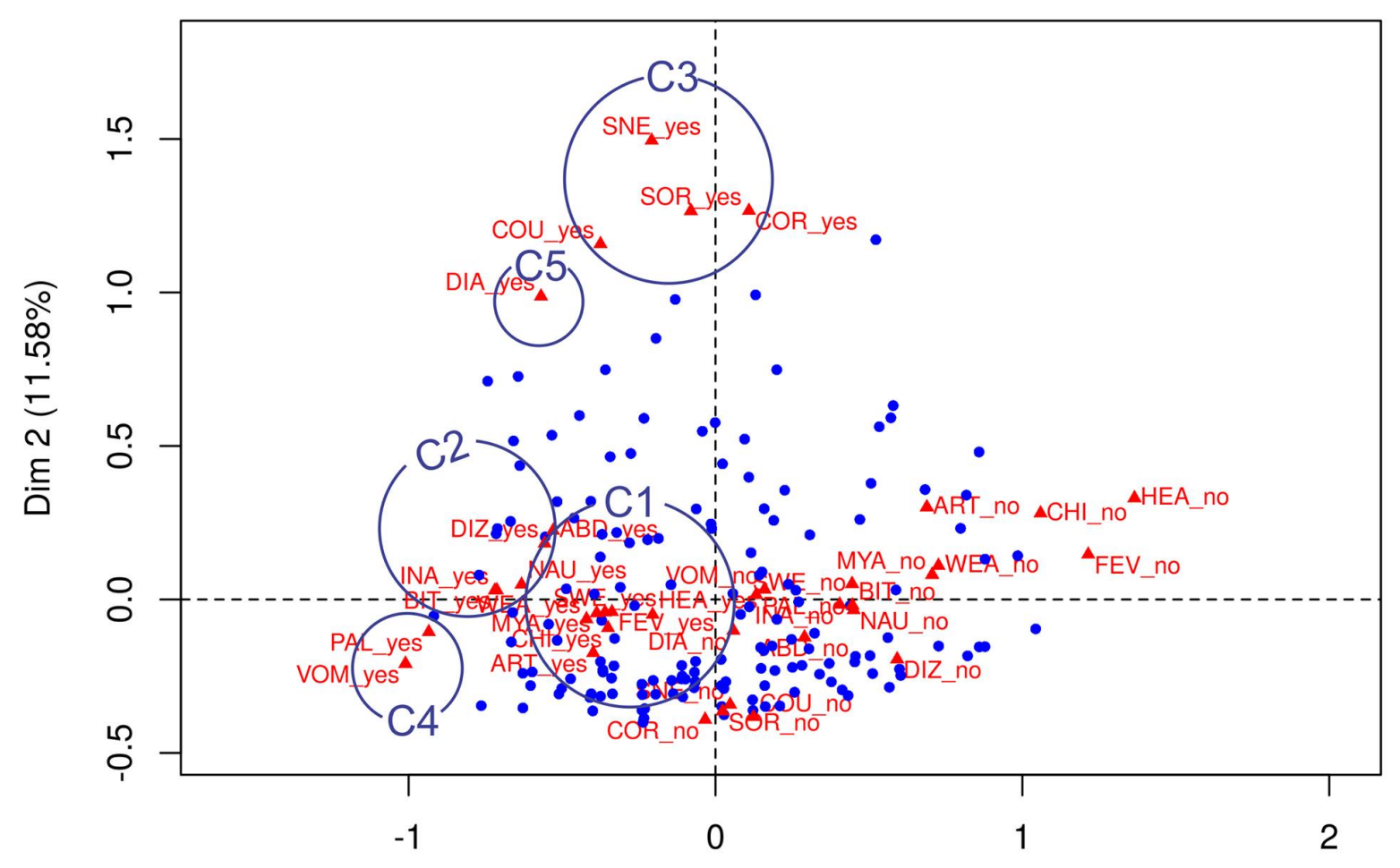

Dim 1 (20.16\%)

757

758 
Figure 3

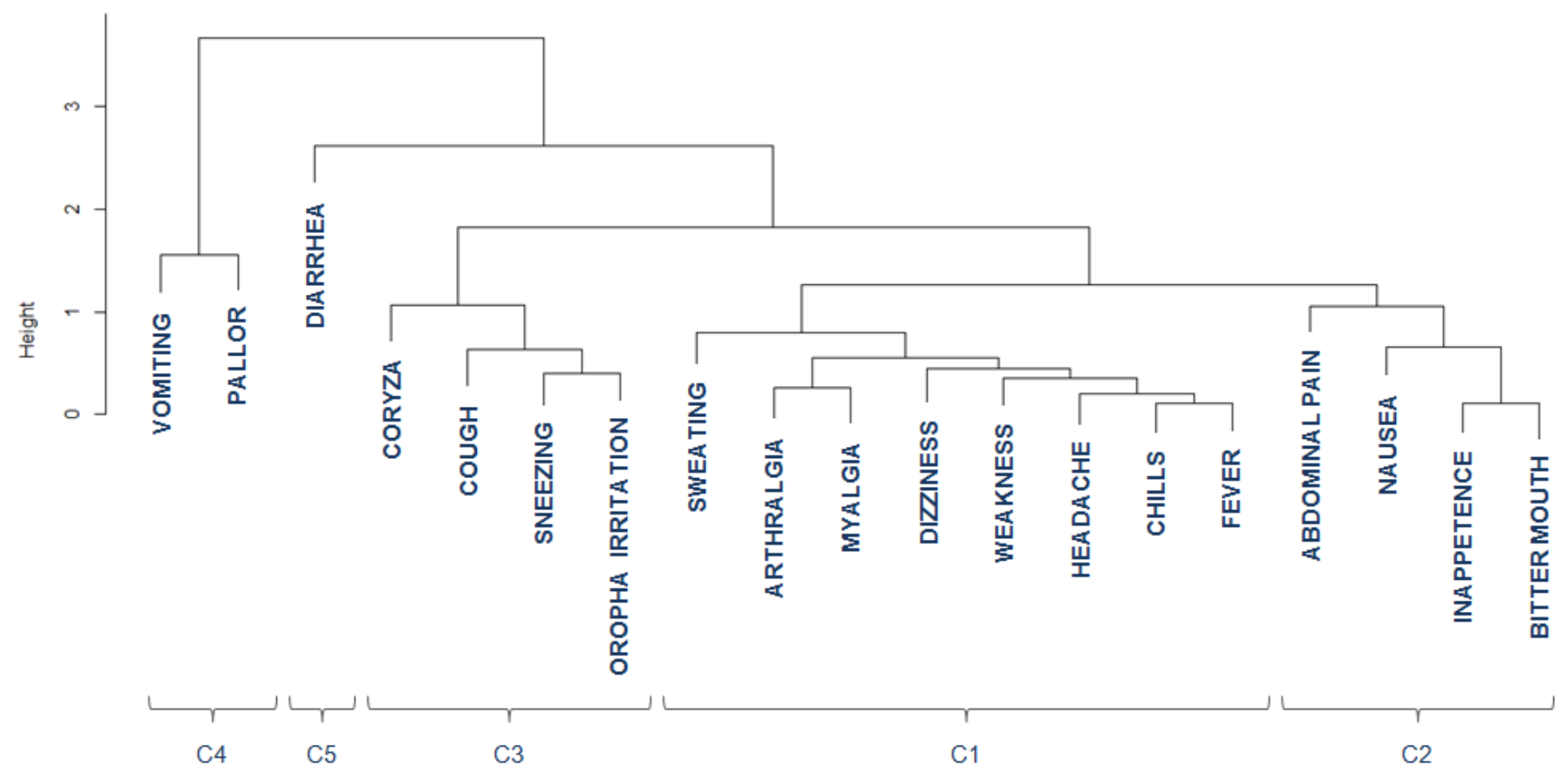

760

761 


\section{Figure 4}

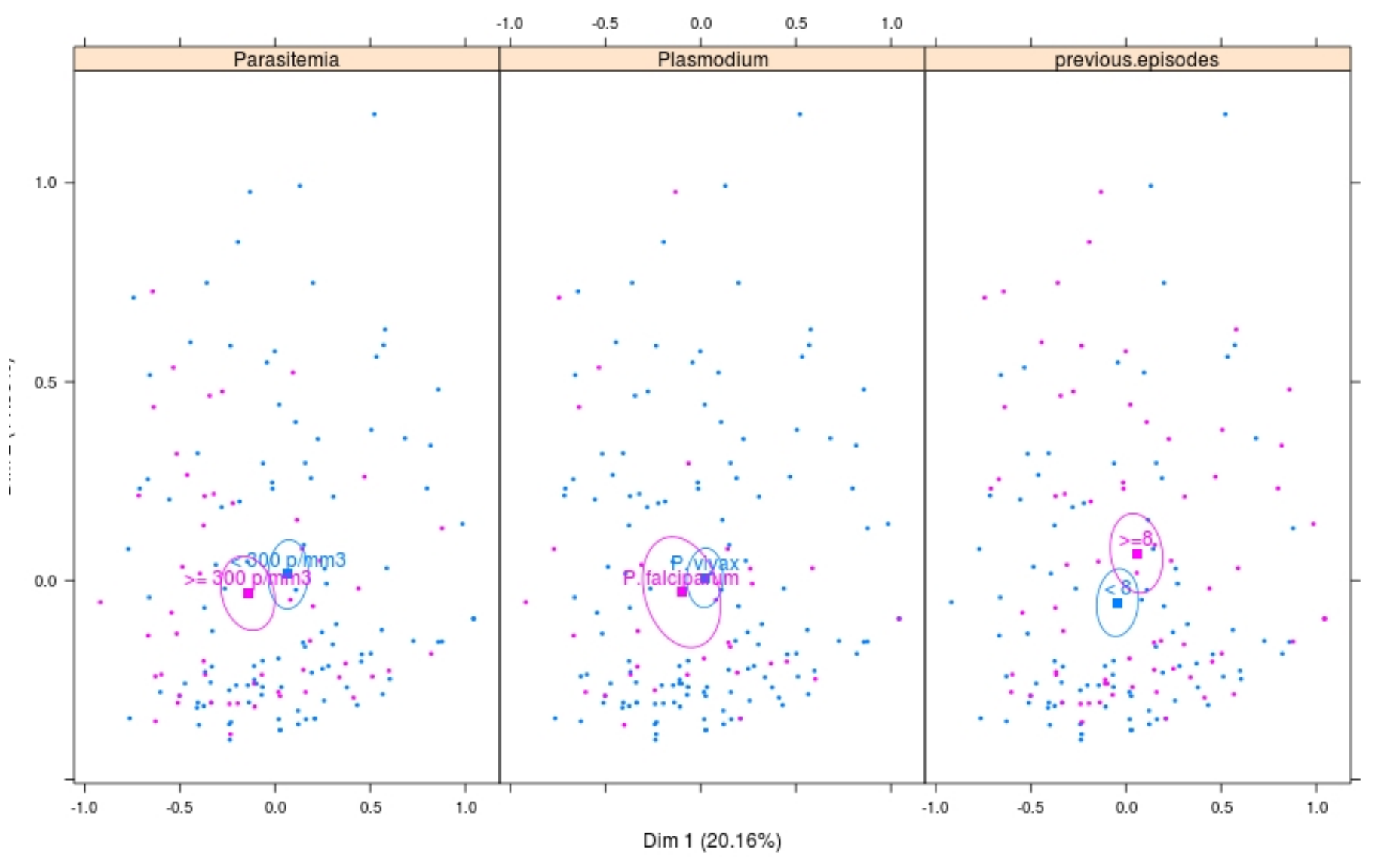

763 
766

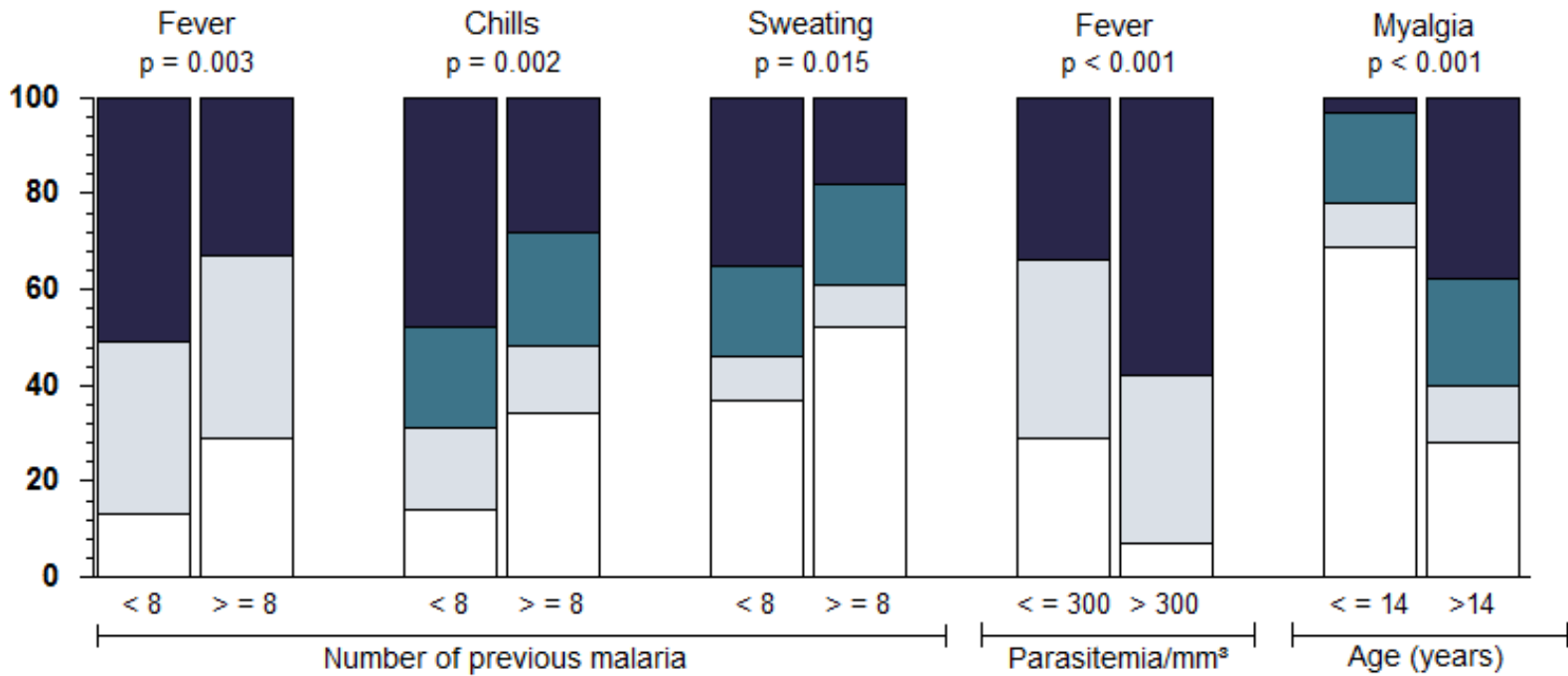




\section{1}

Frequency and intensity of each malaria-related symptom in Mancio Lima (2012-2013).

Numbers on $y$ axis are percentages. The shading pattern of each bar indicates the proportion of patients reporting a given symptom as absent, mild, moderate or severe. $\mathrm{Cl}=$ Algic and fever-related symptoms; $\mathrm{C} 2$ = Gastric symptoms; $\mathrm{C} 3=$ Respiratory symptoms; $\mathrm{C} 4=$ Vomiting and pallor; $\mathrm{C} 5$ = Diarrhoea.

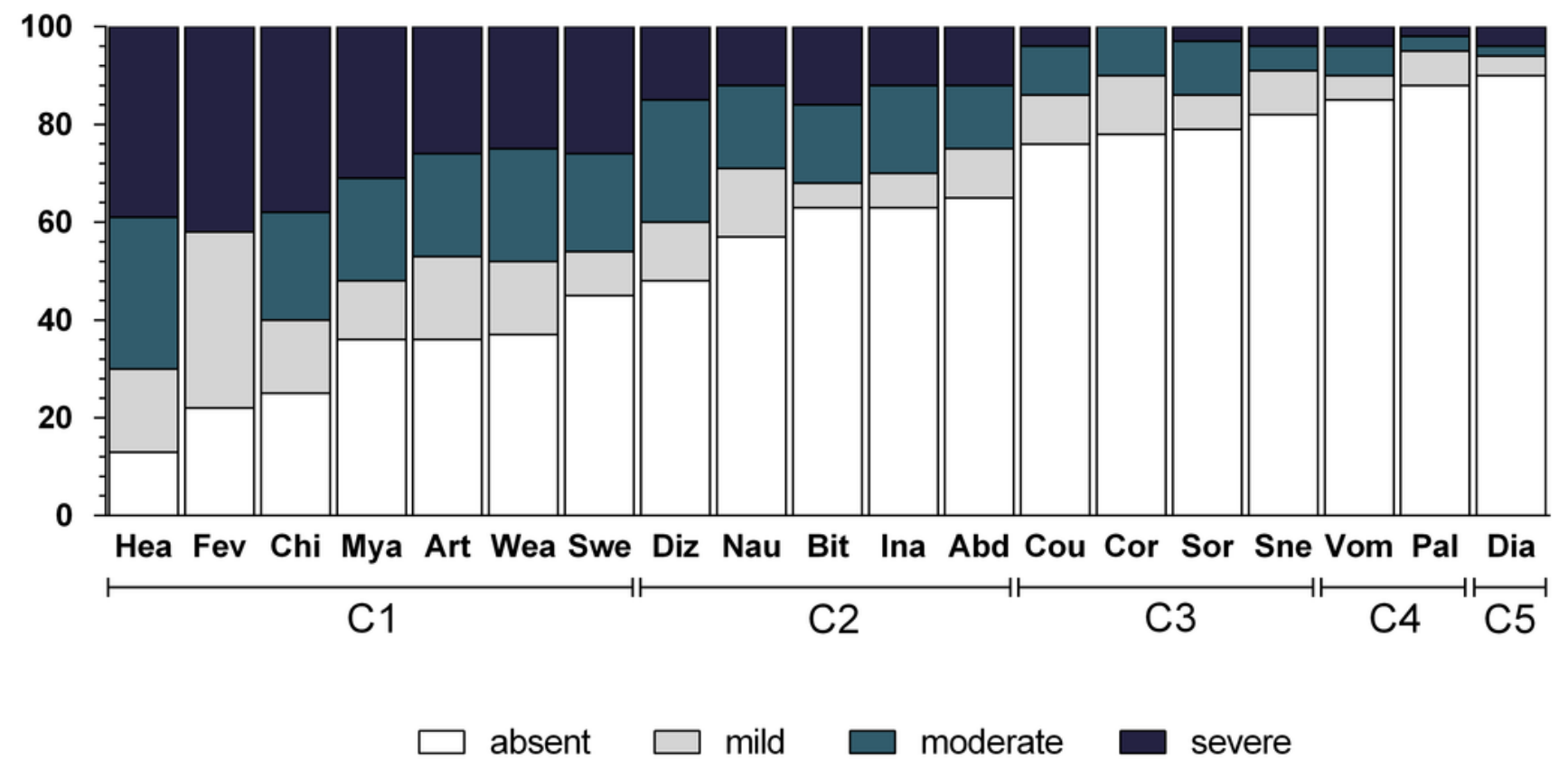


Joint distribution of the correspondence analysis dimensions for qualitative variables (parasitemia, number of previous malaria episodes and malaria species).

- (A) Joint distribution of the correspondence analysis dimensions for qualitative variables (parasitemia, number of previous malaria episodes and malaria species). Dimension 1 and 2 contribute to explain $31.74 \%$ of the variance. The contribution of each symptom in dimension 1 and 2 is represented as a triangle, where 'yes' indicates the contribution of the presence of the symptom, and 'no' indicates the contribution of the absence of the symptom. Subjects are represented as blue dots, and their position in each quadrant demonstrate the referred symptom profile of each individual (near the presence of symptoms or near the absence of symptoms). (B) Joint distribution of the correspondence analysis dimensions for qualitative variables (parasitemia, number of previous malaria episodes and malaria species) with circles indicating groups of symptoms identified in the cluster analysis. $\mathrm{Cl}=$ Algic and feverrelated symptoms; $\mathrm{C2}=$ Gastric symptoms; $\mathrm{C} 3=$ Respiratory symptoms; $\mathrm{C} 4=$ Vomiting and pallor; $\mathrm{C} 5$ = Diarrhoea.
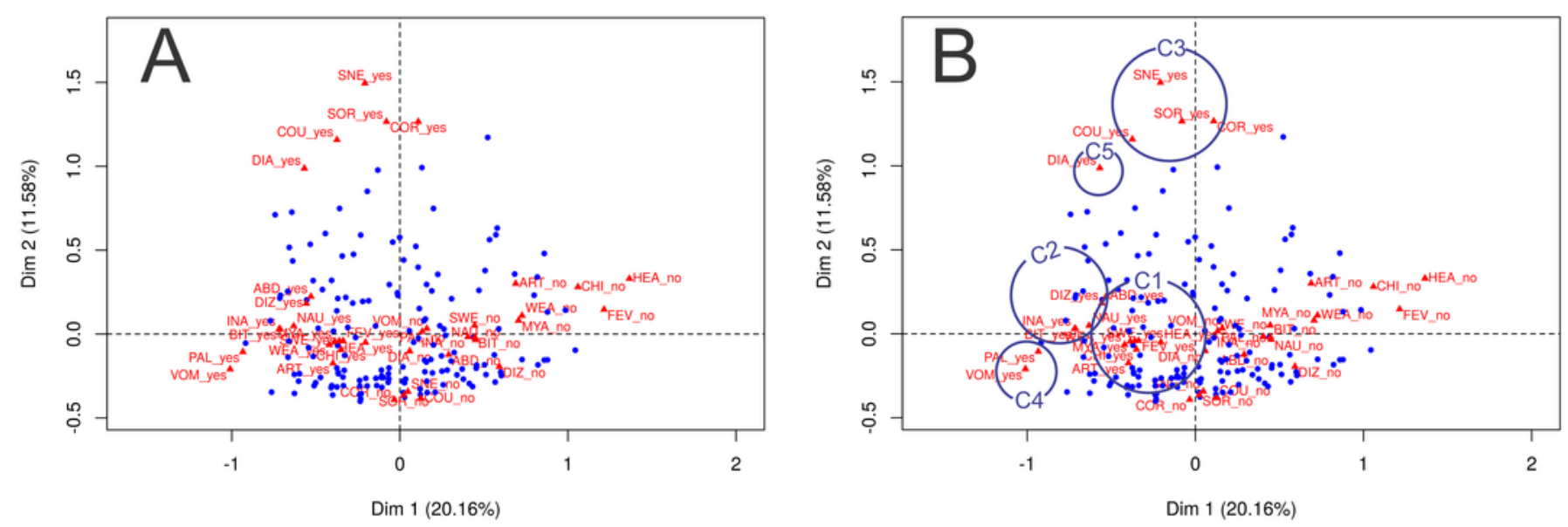
3

Dendrogram of the coordinates of the first two dimensions of the correspondence analysis with clusters of groups

$\mathrm{C} 1=$ Algic and fever-related symptoms; $\mathrm{C2}=$ Gastric symptoms; $\mathrm{C} 3=$ Respiratory symptoms; $\mathrm{C} 4$ = Vomiting and pallor; $\mathrm{C} 5$ = Diarrhoea.

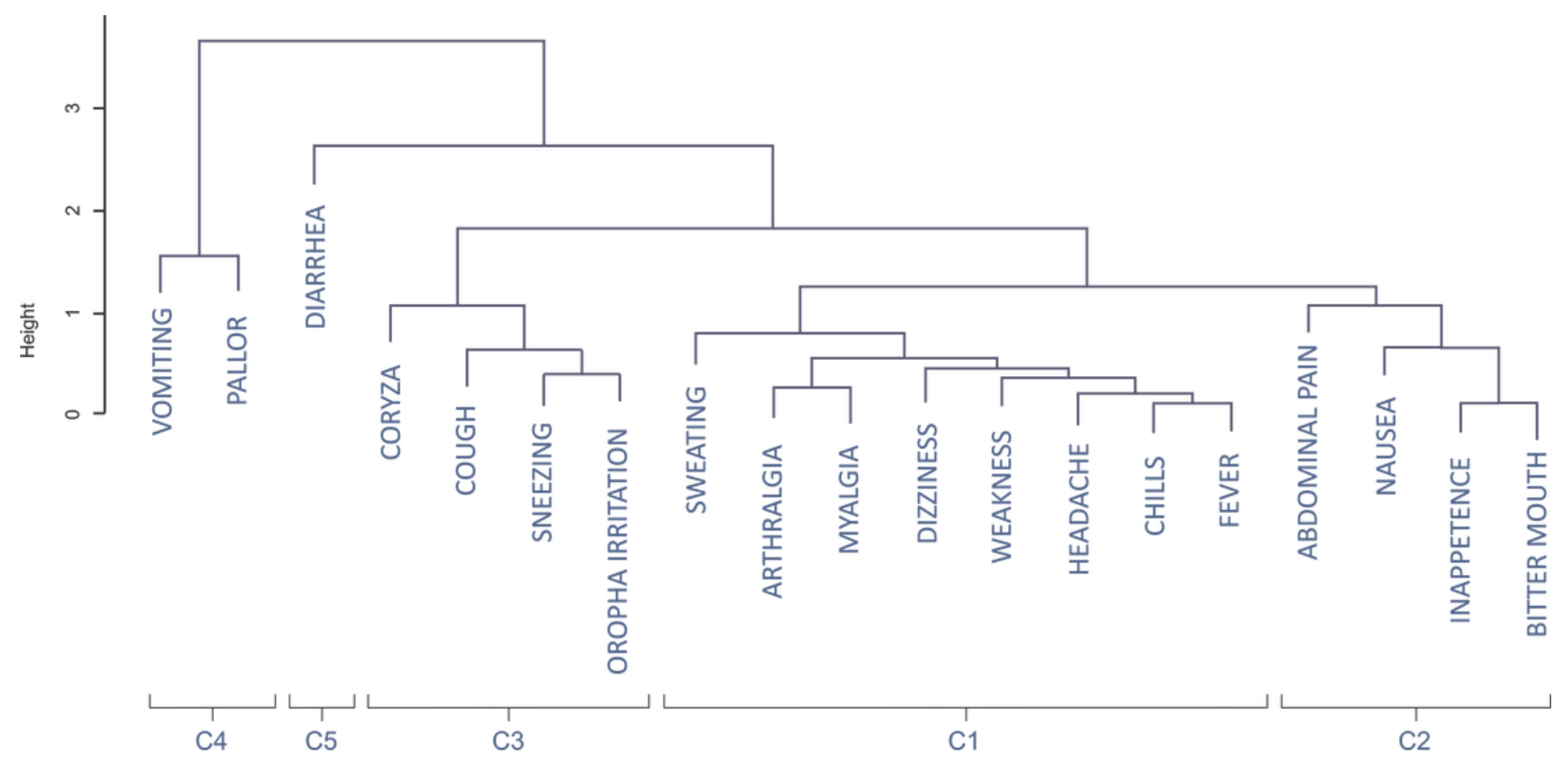




\section{4}

Multiple correspondence analysis classified by Plasmodium species, parasitemia and number of previous malaria episodes

The confidence ellipse delimitates the centroid around each variable. For Parasitemia, ellipses are separated, indicating a good distinction in symptom profile between low and high parasitemia. Patients with higher parasitemia ( $\geq 300$ parasites $/ \mathrm{mm}^{3}$ ) have more symptoms (pink ellipse is seen in the left-hand side of dimension 1) and those with lower parasitemia (< 300 parasites $/ \mathrm{mm}^{3}$ ) tend to have fewer symptoms (blue ellipse represented on the right-hand side of dimension 1). For Plasmodium species, ellipses are superimposed, indicating that the symptom profile shown in each type of malaria is very similar, and therefore malaria species cannot be differentiated using symptoms only. For number of previous episodes of malaria, there is little superimposition of the ellipses, indicating that it is possible to separate between those patients with more than eight previous malaria episodes, who generally experience fewer symptoms (pink ellipse is in the right side of Dimension 1, indicating less symptoms), except for symptoms sore throat, which is more pronounced in these patients (note that the pink ellipse is above the blue ellipse in Dimension 2, indicating that symptoms distributed along dimension 2 are differentiating patients with 8 or more episodes from those with less than 8 episodes). 


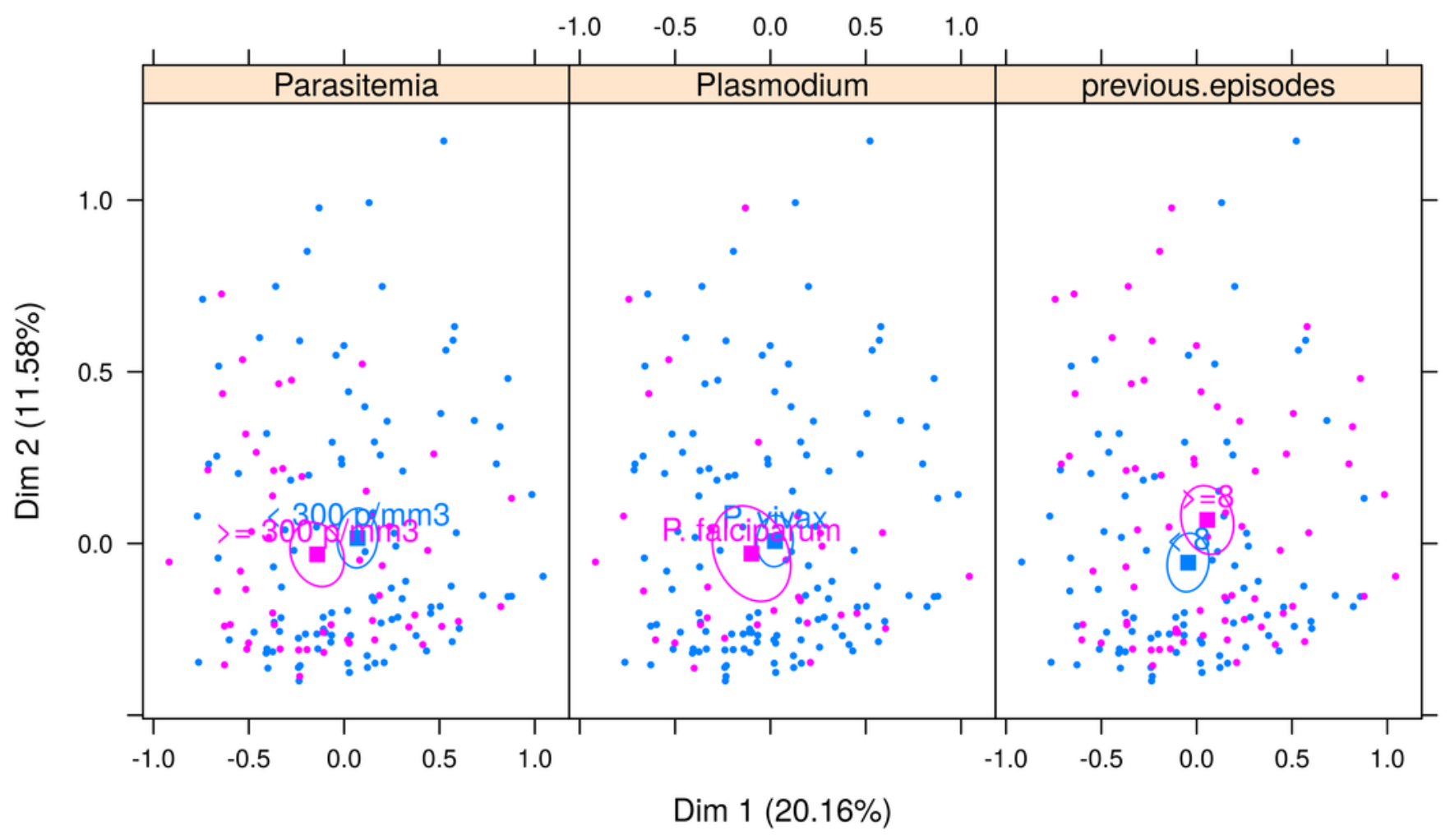




\section{5}

Relationship between symptom intensity and parasitological features (number of previous malaria episodes, parasitemia and age) in Mancio Lima (2012-2013).

Numbers on $y$ axis are percentages. The shading pattern of each bar segment indicates the proportion of patients reporting a given symptom as absent, mild, moderate or severe. $\mathrm{P}$ value $=$ Somers $\mathbf{d}$ test for ordinal variables

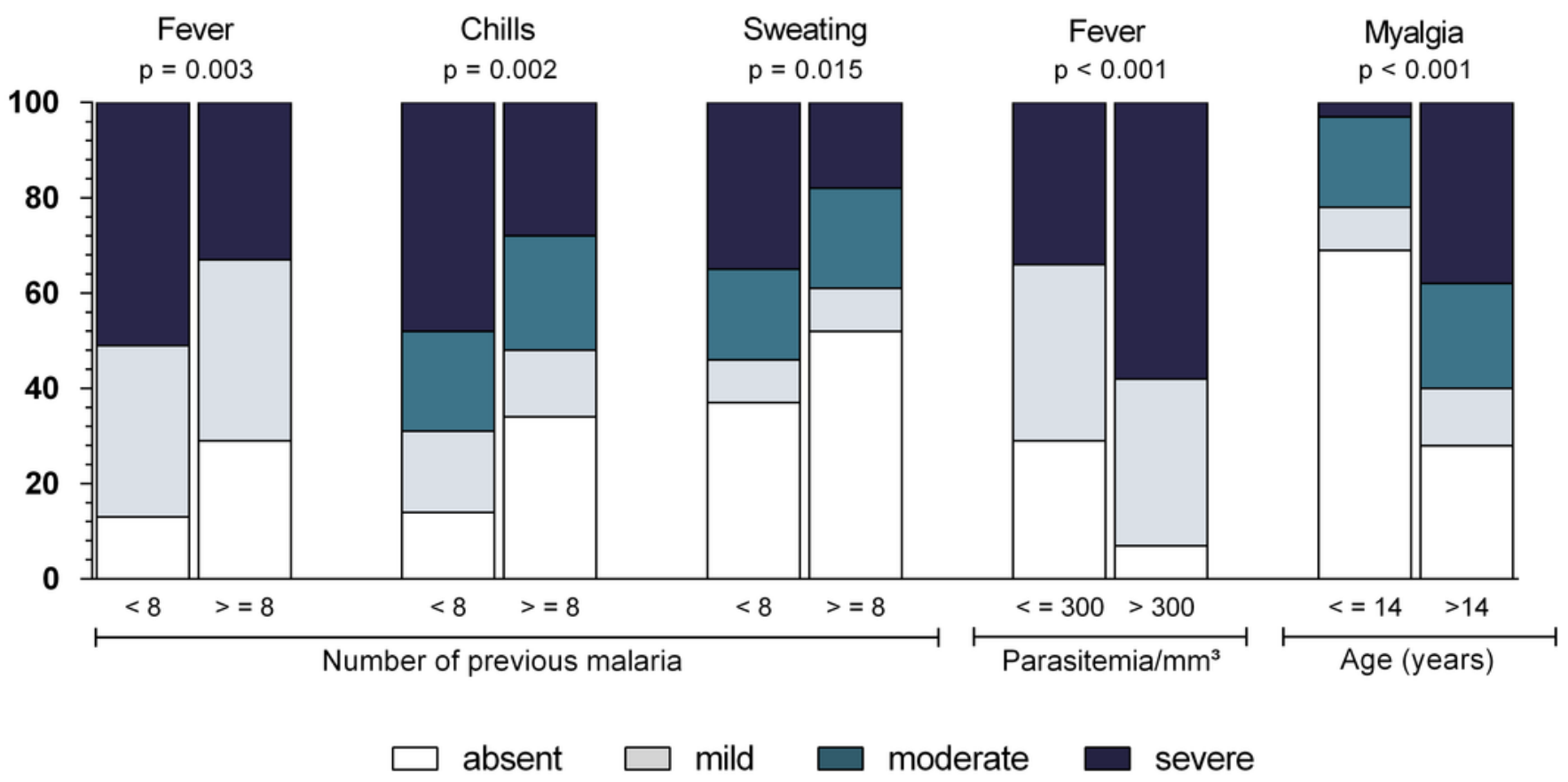




\section{Table $\mathbf{1}$ (on next page)}

Epidemiological and parasitological characteristics of malaria cases, Mancio Lima, 20122013. 
1 Table 1 - Epidemiological and parasitological characteristics of malaria cases, Mancio Lima, 2012-2013.

2

\begin{tabular}{lcc}
\hline Variables & $\mathrm{n}$ & $\%$ \\
\hline Gender & & \\
Female & 76 & 44.4 \\
Male & 95 & 55.6
\end{tabular}

Type of malaria

P. vivax

$137 \quad 80.10$

P. falciparum

$34 \quad 19.10$

Parasitemia

$<200$ parasites $/ \mathrm{mm}^{3}$

$68 \quad 40.00$

$200-300$ parasites $/ \mathrm{mm}^{3}$

$44 \quad 25.90$

$301-500$ parasites $/ \mathrm{mm}^{3}$

$23 \quad 13.50$

501- 10.000 parasites $/ \mathrm{mm}^{3}$

$33 \quad 19.40$

10.001-100.000 parasites $/ \mathrm{mm}^{3}$

$2 \quad 1.20$

Number of previous malaria episodes

\begin{tabular}{lrr} 
None & 5 & 3.03 \\
Only one malaria episode & 13 & 7.88 \\
Between 2 and 7 malaria episodes & 66 & 40.00 \\
More or equal to 8 malaria episodes & 81 & 49.09 \\
\hline
\end{tabular}

3 
Table 2 (on next page)

Frequency of 19 symptoms related to malaria, Mancio Lima, 2012-2013. 
Table 2 - Frequency of 19 symptoms related to malaria, Mancio Lima, 2012-2013.

\begin{tabular}{|c|c|c|c|c|}
\hline $\begin{array}{l}\text { Group of } \\
\text { symptoms }\end{array}$ & Symptom & $\begin{array}{c}\text { P. v } \\
\text { n (\%) }\end{array}$ & $\begin{array}{c}\text { P.f } \\
n(\%) \\
\end{array}$ & $\begin{array}{c}\text { P. v + P.f } \\
n(\%)\end{array}$ \\
\hline \multirow{9}{*}{$\begin{array}{l}\text { Algic and } \\
\text { fever-related } \\
\text { symptoms }\end{array}$} & Headache & 119 (86.9) & $29(85.3)$ & $148(86.5)$ \\
\hline & Fever & $110(80.3)$ & $24(70.6)$ & $134(78.4)$ \\
\hline & Chills & 104 (75.9) & $25(73.5)$ & $129(75.4)$ \\
\hline & Myalgia & $86(62.8)$ & 24 (70.6) & $110(64.3)$ \\
\hline & Arthralgia & $85(62.0)$ & 24 (70.6) & 109 (63.7) \\
\hline & Weakness & $88(64.2)$ & 19 (55.9) & $107(62.6)$ \\
\hline & Sweating & 75 (54.7) & 19 (55.9) & $94(55.0)$ \\
\hline & Dizziness & 67 (48.9) & $22(64.7)$ & $89(52.0)$ \\
\hline & Any symptom & $131(95.6)$ & $32(94.1)$ & $163(95.3)$ \\
\hline \multirow{5}{*}{$\begin{array}{l}\text { Gastric } \\
\text { symptoms }\end{array}$} & Nausea & $57(41.6)$ & $16(47.1)$ & $73(42.7)$ \\
\hline & Bitter mouth & $48(35.0)$ & $16(47.1)$ & $64(37.4)$ \\
\hline & Inappetence & $48(35.0)$ & $15(44.1)$ & $63(36.8)$ \\
\hline & Abdominal pain & 46 (33.6) & $14(41.2)$ & 60 (35.1) \\
\hline & Any symptom & $94(68.5)$ & $29(85.3)$ & 123 (71.9) \\
\hline \multirow{5}{*}{$\begin{array}{l}\text { Respiratory } \\
\text { symptoms }\end{array}$} & Cough & $32(23.4)$ & $9(26.5)$ & $41(24)$ \\
\hline & Coryza & $33(24.1)$ & $5(14.7)$ & $38(22.2)$ \\
\hline & Sore throat & $33(24.1)$ & $3(8.8)$ & $36(21.1)$ \\
\hline & Sneeze & $26(19.0)$ & $5(14.7)$ & 31 (18.1) \\
\hline & Any symptom & $61(44.5)$ & $12(35.3)$ & 73 (42.7) \\
\hline \multirow{3}{*}{$\begin{array}{l}\text { Vomiting and } \\
\text { pallor }\end{array}$} & Vomiting & 19 (13.9) & $6(17.6)$ & 25 (14.6) \\
\hline & Pallor & $14(10.2)$ & $6(17.6)$ & 20 (11.7) \\
\hline & Any symptom & $29(21.2)$ & $8(23.5)$ & $37(21.6)$ \\
\hline Diarrhea & Diarrhea & $11(8.0)$ & $6(17.6)$ & $17(9.9)$ \\
\hline
\end{tabular}


1

Peer) reviewing PDF | (2015:07:5751:1:1:NEW 23 Sep 2015) 
Table 3(on next page)

Relative contributions of the first and second dimensions of the correspondence analysis and $\mathrm{R}^{2}$ values according to symptoms, Mancio Lima, 2012-2013. 
1 Table 3 - Relative contributions of the first and second dimensions of the correspondence analysis and $\mathrm{R}^{2}$ 2 values according to symptoms, Mancio Lima, 2012-2013.

\begin{tabular}{|c|c|c|c|c|c|c|c|}
\hline $\begin{array}{l}\text { Group of } \\
\text { symptoms }\end{array}$ & Symptom & Dimension 1 & Dimension 2 & $\mathrm{R}^{2}$ Dimension 1 & P value 1 & $\mathrm{R}^{2}$ Dimension 2 & P value 2 \\
\hline \multirow{8}{*}{$\begin{array}{l}\text { Algic and fever- } \\
\text { related } \\
\text { symptoms }\end{array}$} & Headache & 0.279 & 0.016 & 0.279 & $<0.001$ & & \\
\hline & Fever & 0.409 & 0.005 & 0.409 & $<0.001$ & & \\
\hline & Chills & 0.370 & 0.026 & 0.370 & $<0.001$ & 0.026 & 0.04 \\
\hline & Myalgia & 0.273 & 0.003 & 0.273 & $<0.001$ & & \\
\hline & Arthralgia & 0.274 & 0.052 & 0.274 & $<0.001$ & 0.052 & 0.003 \\
\hline & Weakness & 0.305 & 0.007 & 0.305 & $<0.001$ & & \\
\hline & Sweating & 0.160 & 0.002 & 0.160 & $<0.001$ & & \\
\hline & Dizziness & 0.329 & 0.035 & 0.329 & $<0.001$ & 0.035 & 0.016 \\
\hline \multirow{4}{*}{$\begin{array}{l}\text { Gastric } \\
\text { symptoms }\end{array}$} & Nausea & 0.284 & 0.001 & 0.284 & $<0.001$ & & \\
\hline & $\begin{array}{l}\text { Bitter } \\
\text { mouth }\end{array}$ & 0.317 & 0.001 & 0.317 & $<0.001$ & & \\
\hline & Inappetence & 0.291 & 0.001 & 0.291 & $<0.001$ & & \\
\hline & $\begin{array}{l}\text { Abdominal } \\
\text { pain }\end{array}$ & 0.153 & 0.027 & 0.153 & $<0.001$ & 0.027 & 0.035 \\
\hline \multirow{4}{*}{$\begin{array}{l}\text { Respiratory } \\
\text { symptoms }\end{array}$} & Cough & 0.046 & 0.443 & 0.046 & 0.006 & 0.443 & $<0.001$ \\
\hline & Coryza & 0.003 & 0.495 & & $<0.001$ & 0.443 & $<0.001$ \\
\hline & Sore throat & 0.001 & 0.461 & & $<0.001$ & 0.461 & $<0.001$ \\
\hline & Sneeze & 0.009 & 0.511 & & & 0.511 & $<0.001$ \\
\hline \multirow{2}{*}{$\begin{array}{l}\text { Vomiting and } \\
\text { pallor }\end{array}$} & Vomiting & 0.161 & 0.006 & & 0.161 & & \\
\hline & Pallor & 0.123 & 0.001 & & 0.123 & & \\
\hline Diarrhea & Diarrhea & 0.033 & 0.100 & & 0.033 & 0.100 & $<0.001$ \\
\hline
\end{tabular}




\section{Table 4 (on next page)}

Association between symptoms and clinical features in malaria cases, Mancio Lima, 2012-2013 
1 Table 4 - Association between symptoms and clinical features in malaria cases, Mancio Lima, 2012-2013 2

\begin{tabular}{|c|c|c|c|}
\hline \multicolumn{4}{|c|}{ Outcome: Parasitemia higher than 300 parasites $/ \mathrm{mm}^{3}$} \\
\hline & OR & $95 \% \mathrm{Cl}$ & $P$ value \\
\hline Presence of fever & 5.4 & $1.81-16.12$ & 0.003 \\
\hline Presence of vomiting & 2.51 & $1.06-5.94$ & 0.036 \\
\hline Presence of dizziness & 2.21 & $1.14-4.26$ & 0.018 \\
\hline Presence of weakness & 2.74 & $1.33-5.63$ & 0.006 \\
\hline
\end{tabular}

\begin{tabular}{lccc}
\hline \multicolumn{4}{l}{ Outcome: Age older than 14 years old } \\
& OR & $95 \% \mathrm{Cl}$ & P value \\
\hline Presence of arthralgia & 5.44 & $2.37-12.52$ & $<0.001$ \\
& & & \\
Presence of myalgia & 5.64 & $2.45-12.99$ & $<0.001$ \\
& & & \\
\hline
\end{tabular}

Outcome: Number of previous malaria equal or higher than 8

\begin{tabular}{lccc}
\hline & OR & $95 \% \mathrm{Cl}$ & P value \\
\hline Presence of fever & 0.3 & $0.18-0.84$ & 0.017 \\
Presence of chills & 0.44 & $0.21-0.91$ & 0.027 \\
Presence of sore throat & 2.36 & $1.1-5.04$ & 0.027 \\
\hline
\end{tabular}

